\title{
Mutation accumulation in chromosomal inversions maintains wing pattern polymorphism in a butterfly
}

\author{
Paul Jay ${ }^{1 *}$, Mathieu Chouteau ${ }^{1,2 *}$, Annabel Whibley ${ }^{3}$, Héloïse Bastide $^{4}$, Violaine Llaurens ${ }^{4}$, Hugues Parrinello ${ }^{5}$, and Mathieu \\ Joron $^{1}$ \\ ${ }^{1}$ CEFE, CNRS, Université de Montpellier, Université Paul Valery, Montpellier 3, EPHE, IRD, Montpellier, France \\ ${ }^{2}$ LEEISA, USR 63456, Université De Guyane, CNRS Guyane, IFREMER Guyane, 275 route de Montabo, 797334 Cayenne, French Guiana \\ ${ }^{3}$ School of Biological Sciences, University of Auckland, Auckland, New Zealand \\ ${ }^{4}$ ISYEB, UMR7205 CNRS-MNHN-9UPMC-EPHE, Muséum national d'Histoire naturelle, CP 50,45 rue Buffon, 75005 Paris, 10France. \\ ${ }^{5}$ MGX, Biocampus Montpellier, CNRS, INSERM, Université Montpellier, Montpellier, France \\ *These authors contributed equally.
}

\begin{abstract}
While natural selection favours the fittest genotype, polymorphisms are maintained over evolutionary timescales in numerous species. Why these long-lived polymorphisms are often associated with chromosomal rearrangements remains obscure. Combining genome assemblies, population genomic analyses, and fitness assays, we studied the factors maintaining multiple mimetic morphs in the butterfly Heliconius numata. We show that the polymorphism is maintained because three chromosomal inversions controlling wing patterns express a recessive mutational load, which prevents their fixation despite their ecological advantage. Since inversions suppress recombination and hamper genetic purging, their formation fostered the capture and accumulation of deleterious variants. This suggests that many complex polymorphisms, instead of representing adaptations to the existence of alternative ecological optima, could be maintained primarily because chromosomal rearrangements are prone to carrying recessive harmful mutations.
\end{abstract}

Heliconius | Polymorphism | Supergene | Degeneration | Inversion | Load Correspondence: paul.jay@cefe.cnrs.fr, mathieu.chouteau@cnrs.fr, math ieu.joron@cefe.cnrs.fr

Polymorphic complex traits, which implicate the coordination of multiple elements of phenotype, are often controlled by special genetic architectures involving chromosomal rearrangements. Examples include dimorphic social organization in several ant species (1), coloration and behavioral polymorphisms in many birds and butterflies (2-6), dimorphic flower morphology in plants (7), as well as the extreme cases provided by sexual dimorphism encoded by the extensively rearranged sex chromosomes. Why these polymorphisms arise is a long-standing question in biology (8-12).

The so-called supergenes controlling these striking polymorphisms are characterized by the suppression of recombination between linked loci, often through polymorphic chromosomal rearrangements which are thought to preserve alternative combinations of co-adapted alleles $(1,4,5,7,12)$. The encoded phenotypes are often assumed to reflect the existence of multiple, distinct adaptive optima, and are frequently associated with antagonistic ecological factors such as differential survival or mating success $(3,13-15)$. Yet why and how alternative chromosomal forms become associated with complex life-history variation and ecological trade-offs is not understood.
The Amazonian butterfly Heliconius numata displays wing pattern polymorphism with up to seven morphs coexisting within a single locality, each one engaged in warning color mimicry with distinct groups of toxic species. Adult morphs vary in mimicry protection against predators and in mating success via disassortative mate preferences $(13,16)$. Polymorphic inversions at the mimicry locus on chromosome 15 (supergene P) form three distinct haplotypes (5). The standard, ancestral haplotype constitutes the class of recessive $\mathrm{P}$ alleles and is found, for example, in the widespread morph silvana. Two classes of derived haplotypes are known, both associated with a chromosomal inversion called $\mathrm{P}_{1}$ ( $\sim 400 \mathrm{~kb}, 21$ genes), each conferring increased protection against predatory attacks via mimicry. The first derived haplotype, encoding the morph bicoloratus, carries $\mathrm{P}_{1}$ alone; the second class of derived haplotypes carries $\mathrm{P}_{1}$ linked with additional yet still uncharacterized rearrangements (called BP2 in (5)) and occurs in morphs which typically exhibit intermediate levels of dominance, such as tarapotensis and arcuella. Inversion polymorphism and supergene formation originated via the introgression of $\mathrm{P}_{1}$ from the $H$. pardalinus lineage (17). The series of chromosomal rearrangements initiated by introgression allows us to unravel the stepwise process by which structural variation has become associated with directional and balancing selection.

Comparative analysis of de novo genome assemblies of 12 $H$. numata individuals revealed a history of supergene formation characterized by the sequential accretion of three adjacent inversions with breakpoint reuse. Pairwise alignment of assemblies shows that all derived haplotypes belonging to the intermediate dominant allelic class display two newlydescribed inversions: $P_{2}\left(200 \mathrm{~kb}, 15\right.$ genes), adjacent to $P_{1}$, and the longer $\mathrm{P}_{3}$ (1150 kb, 71 genes), adjacent to $\mathrm{P}_{2}$ (Fig 1A, Sup. Fig. S1, Sup. Fig. S2). Sliding-window PCA along the supergene region confirmed the dominance of derived arrangements (denoted $\mathrm{Hn} 1$ and $\mathrm{Hn} 123$ ) to the ancestral arrangement (denoted $\mathrm{Hn} 0$ ) and their prevalence across all populations of the Amazon (Fig 1B, Fig 1C, Sup. Fig. S3, Sup. Fig. S4). Multiple genes in the inverted regions showed significant differential expression compared to ancestral seg- 
A
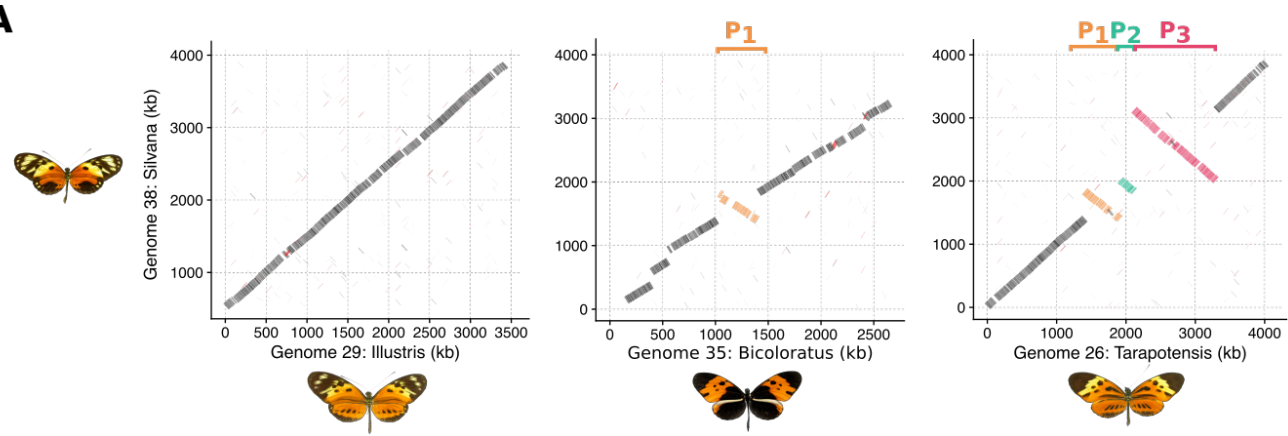

B

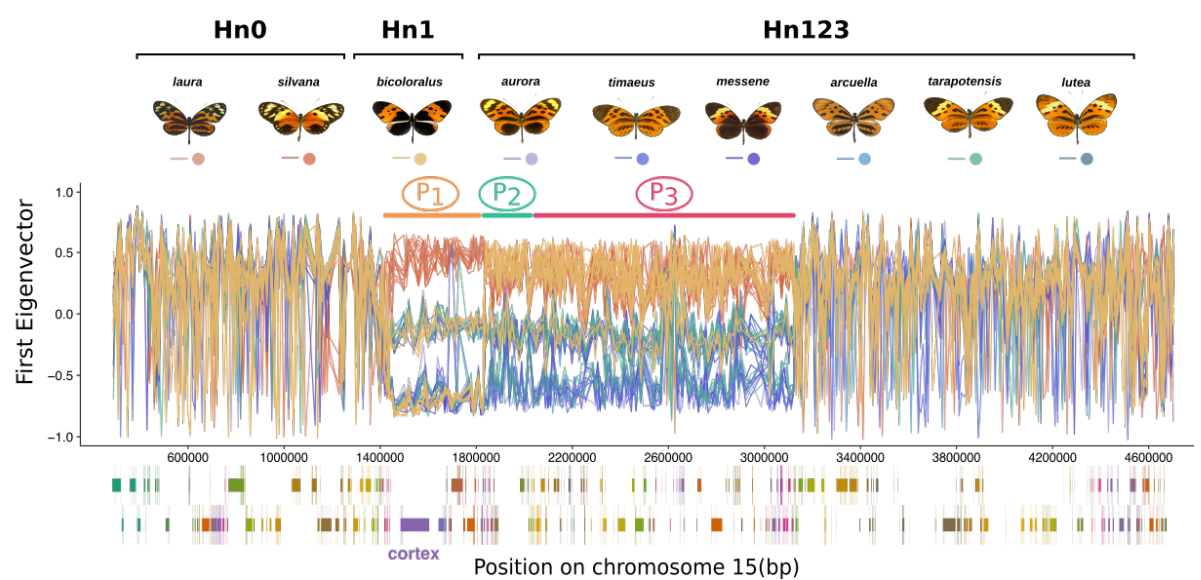

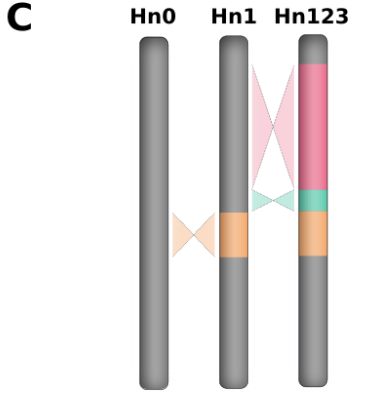

D

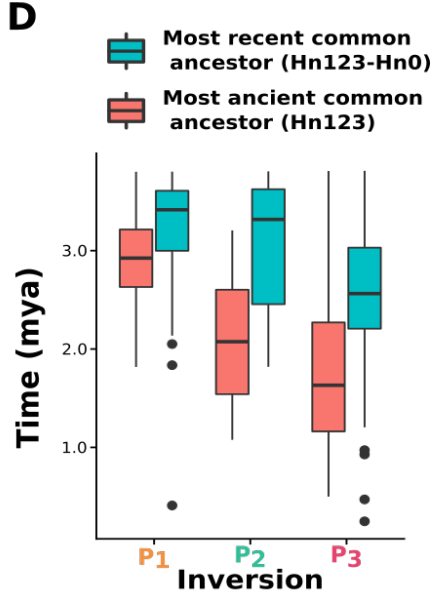

Fig. 1. Genomic architecture of the $\boldsymbol{H}$. numata wing pattern polymorphism

A. Alignment of the genome assemblies from $4 \mathrm{H}$. numata morphs across the supergene region on chromosome 15. B. Sliding window Principal Component Analysis (PCA) computed along the supergene (non-overlapping $5 \mathrm{~kb}$ windows). For clarity, only a subset of morphs are shown here (full dataset presented in Sup. Fig. S3). Each colored line represents the variation in the position of a specimen on the first PCA axis along chromosome 15 . Within the inversions, individual genomes are characterized by one of three genotypes: homozygous for the inversion (down), heterozygous (middle), homozygous for the standard arrangement (top). The gene annotation track is shown under the plot, with the forward strand in the lower panel and the reverse strand in the upper panel. Each gene is represented by a different colour $\mathbf{C}$. Structure of the $H$. numata supergene $\mathrm{P}$. Three chromosome types are found in $H$. numata populations, carrying the ancestral gene order (Hn0), inversion $\mathrm{P}_{1}$ ( $\left.\mathrm{Hn} 1\right)$, or inversions $\mathrm{P}_{1}, \mathrm{P}_{2}$ and $\mathrm{P}_{3}$ ( $\mathrm{Hn} 123)$. D. Analysis of divergence times between $\mathrm{Hn} 123$ and $\mathrm{Hn} 0$ at inversions segment. The TMRCA between $\mathrm{Hn} 123$ and $\mathrm{Hn} 0$ and the most ancient common ancestor of Hn123 provide respectively the upper and lower bound of the inversions formation time. Boxplots display the distribution of estimated times computed on $5 \mathrm{~kb}$ sliding window across the supergene (estimates plotted along the supergene presented in Sup. Fig. S7).Time intervals are consistent with the stepwise accretion of $P_{1}$, $P_{2}$ and $P_{3}$, but the simultaneous origin of $\mathrm{P}_{2}$ and $\mathrm{P}_{3}$ cannot be formally rejected.

ments, but this likely reflects divergence rather than direct breakpoint effects (Sup. Fig. S5). Indeed, none of the breakpoints of $\mathrm{P}_{1}, \mathrm{P}_{2}$ or $\mathrm{P}_{3}$ fell within a gene, and no transcript found in $\mathrm{Hn} 0$ specimens was missing, disrupted, or differentially spliced in specimens with inversions (Hn1 and Hn123).

In contrast to the introgressive origin of $\mathrm{P}_{1}$ (Sup Fig. S6, (17)), inversions $P_{2}$ and $P_{3}$ are younger and originated within the $H$. numata lineage. Upper and lower estimates of inversion ages, obtained by determining the most recent coalescence events between $\mathrm{Hn} 0+\mathrm{Hn} 1$ and $\mathrm{Hn} 123$, and within Hn123, respectively, suggest that the P supergene has evolved in three steps, involving the introgression of $\mathrm{P}_{1}$ followed by the successive occurrence of $\mathrm{P}_{2}$ and $\mathrm{P}_{3}$ between ca. 1.8 and 3.0 Mya (Fig. 1D, Sup. Fig. S7). Haplotypes show sizeable peaks of differentiation (Fst) across inversion blocks (Sup. Fig. S8), reflecting their distinct histories of recombination suppression and confirming the stepwise accretion of these inversions. The three adjacent inversions underlying the mimicry polymorphism of $H$. numata are therefore of distinct ages and originated in distinct lineages, which provides an opportunity to partition their mutational history and distinguish the consequences of their formation from those resulting from their maintenance in a polymorphism.
Since chromosomal regions carrying inversions rarely form chiasma during meiosis, recombination is strongly reduced among haplotypes with opposite orientations (18). Recombination suppression between structural alleles is predicted to lead to inefficient purging of deleterious variants and therefore to the accumulation of deleterious mutations and transposable elements (TEs) (19). Consistent with this prediction, estimation of the TE dynamics obtained by computing whole genome TE divergence supports a recent burst of TE insertion within the inversions, reported particularly by TEs belonging to the RC, DNA and LINE classes (Fig. 2A, Fig. 2B). Inverted haplotypes show a significant size increase (mean $=+9.47 \%$ ) compared to their corresponding noninverted region in $\mathrm{Hn} 0$ (Fig. 2C) and this expansion was caused primarily $(71.8 \%$, Fig. $2 \mathrm{~A})$ by recent TE insertions from these classes (Fig. 2B, Sup. Fig. S9).

To investigate the impact of polymorphic inversions on the accumulation of deleterious mutations, we calculated, independently on inverted and non-inverted segments, the rate of non-synonymous to synonymous polymorphism ( $\mathrm{pN} / \mathrm{pS})$, the rate of non-synonymous to synonymous substitution $(\mathrm{dN} / \mathrm{dS})$ and the direction of selection (DoS, (20)). Consistent with a low efficiency of selection in eliminating deleterious vari- 

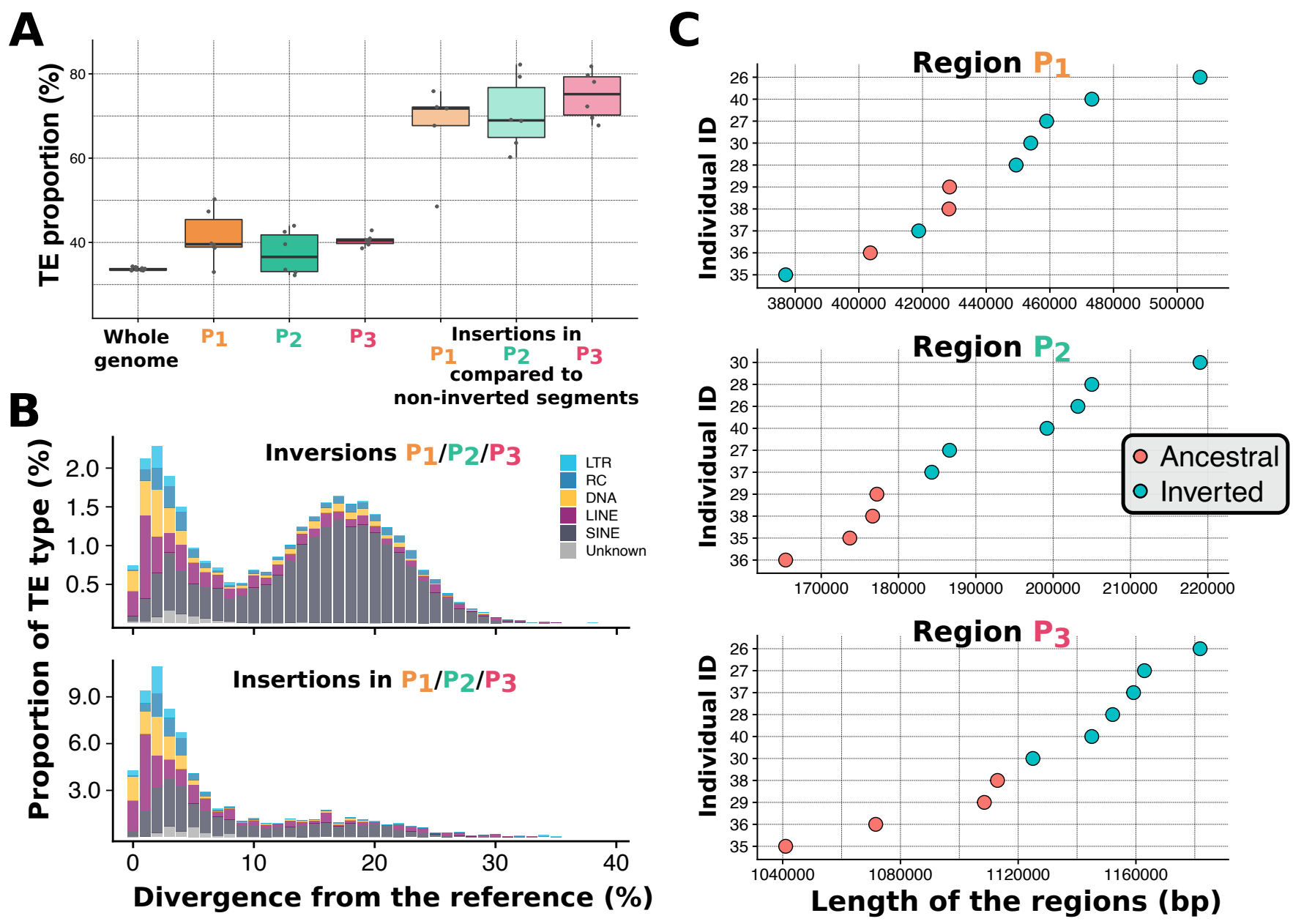

Fig. 2. Variation in inversion size due to accumulation of transposable elements.

A. Proportion of transposable elements in the whole genome, in the 3 inversions, and in the region present uniquely in inversion $P_{1}, P_{2}$ or $P_{3}$ and not in ancestral non-inverted haplotype -i.e. sequences that were inserted in $\mathrm{P}_{1}, \mathrm{P}_{2}$, or $\mathrm{P}_{3}$. Insertions in inversions are mostly transposable elements. $\mathbf{B}$. Timing of insertion, in units of nucleotide divergence, for the distinct classes of transposable elements found in inversions or only in sequences that were inserted in $P_{1}$, $P_{2}$, or $P_{3}$. Recently active TEs (RC, DNA and LINE) are those that have accumulated within inversions. C. Size comparisons of orthologous standard and inverted chromosomal segments. Inverted haplotypes are longer than haplotypes with the ancestral gene order.

ants, $\mathrm{P}_{1}, \mathrm{P}_{2}$, and $\mathrm{P}_{3}$ were all found to be enriched in nonsynonymous relative to synonymous polymorphisms compared to the whole genome and to non-inverted ancestral segments $\left(\mathrm{pN} / \mathrm{pS}_{\mathrm{P} 1}=0.83, \mathrm{pN} / \mathrm{pS}_{\mathrm{P} 2}=0.54, \mathrm{pN} / \mathrm{pS}_{\mathrm{P} 3}=0.49\right.$, Fig. 3A, Sup. Tab. S12). The inversions were also found to be under negative selection $\left(\operatorname{DoS}_{\mathrm{P} 1}=-0.136, \mathrm{DoS}_{\mathrm{P} 2}=-0.087\right.$, $\left.\operatorname{DoS}_{\mathrm{P} 3}=-0.079\right)$, with values reflecting their sequential origin (Fig. 3A, Sup. Tab. S12). Because $\mathrm{P}_{1}$ was introgressed from the $H$. pardalinus lineage (Sup. Fig. S6, (17)), mutations that accumulated in $\mathrm{P}_{1}$ before the introgression (i.e. shared with $H$. pardalinus) could be distinguished from those arising after supergene formation in $H$. numata (i.e. unique to $\mathrm{Hn} 1$ and Hn123). This revealed that non-synonymous mutations which existed in the $\mathrm{P}_{1}$ segment before the introgression underwent a high rate of fixation in $H$. pardalinus $(\mathrm{dN} / \mathrm{dS}$ $=0.78$, Sup. Fig. S10), and in H. numata $(\mathrm{dN} / \mathrm{dS}=1.33$, Fig 3B), suggesting that both the formation of $\mathrm{P}_{1}$ and its introgression led to the fixation of deleterious mutations. By contrast, $99.9 \%$ of the mutations that accumulated in coding regions of $\mathrm{P}_{1}$ after its introgression -i.e. after supergene formation- remain polymorphic in $\mathrm{Hn} 1 / \mathrm{Hn} 123$ and a high proportion of them are non-synonymous $(\mathrm{dN} / \mathrm{dS}=0.00$, $\mathrm{pN} / \mathrm{pS}=0.978, \mathrm{DoS}=-0.49$, Fig 3B, Sup. Tab. S12). Taken together, these results suggest that the inversions have captured and accumulated deleterious mutations during their evolution, presumably owing to bottlenecks generated by their formation and to recombination suppression with their ancestral, coexisting counterparts

Inversions with an accumulated mutational load are expected to incur a fitness cost. Indeed, $H$. numata inversions were found to have detrimental effects on larval survival in homozygotes. When comparing survival among $\mathrm{P}$ genotypes from 1016 genotyped F2 progeny, and controlling for genome-wide inbreeding depression, homozygotes for a derived haplotype showed a far lower survival than other genotypes, with only $6.2 \%$ of $\mathrm{Hn} 1 / \mathrm{Hn} 1$ larvae and $31.3 \%$ of the Hn123/Hn123 larvae surviving to the adult stage (GLMM within-family and genotype analyses, Fig. 4A). By contrast, ancestral homozygotes $\mathrm{Hn} 0 / \mathrm{Hn} 0$ had a good survival rate $(77.6 \%)$, and all heterozygous haplotype combinations (Hn0/Hn1; Hn1/Hn123; Hn0/Hn123) displayed similar survival. Inversions therefore harbor fully recessive variants 

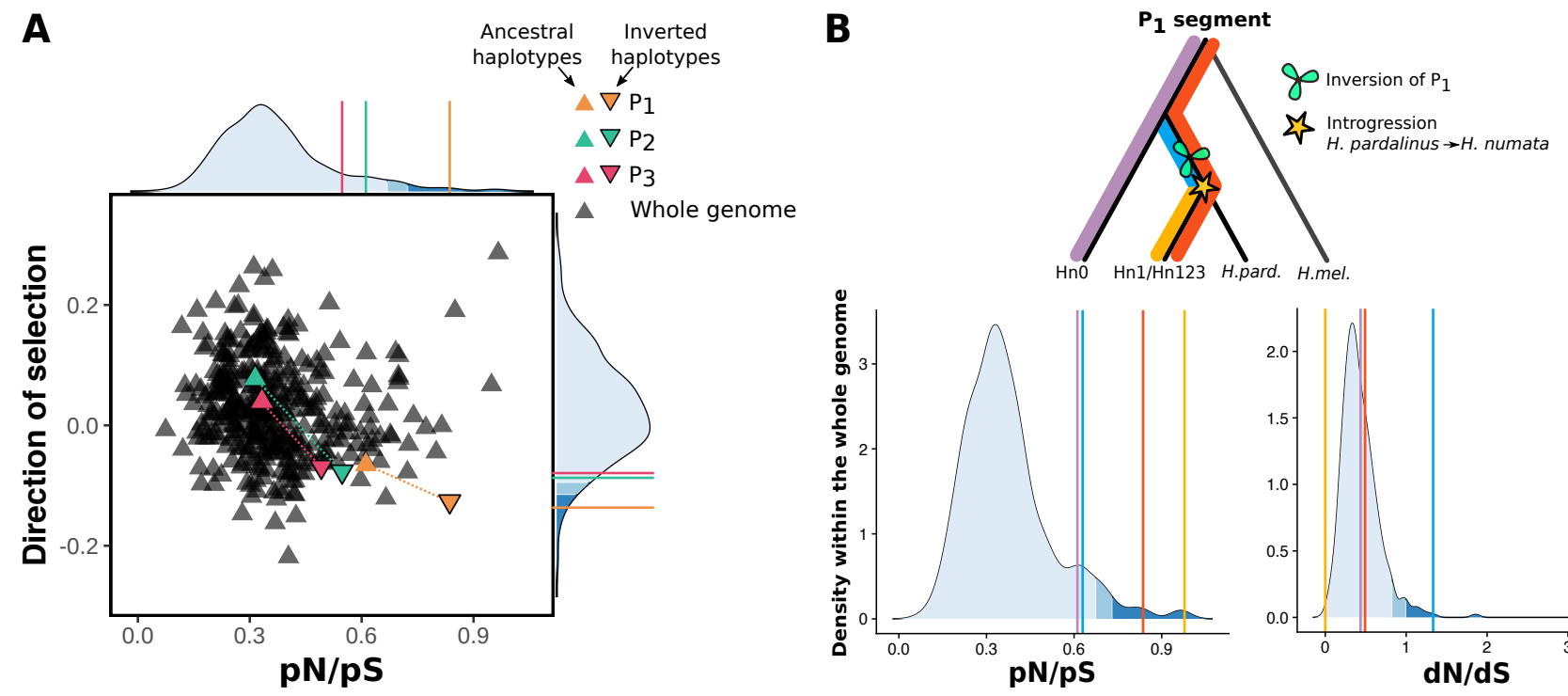

Fig. 3. Accumulation of deleterious variants in inversions

A. Direction of selection and ratio of non-synonymous to synonymous polymorphisms (pN/pS) ratio, computed on $500 \mathrm{~kb}$ windows genome-wide and in the inversions segments, for both inverted and non-inverted haplotypes. Only genes with coding sequences $>5 \mathrm{~kb}(\mathrm{n}=6364)$ were retained in this analysis. Inversions tend to be under negative selection and to accumulate non-synonymous polymorphism. B. Ratios of non-synonymous to synonymous substitutions (dN/dS) and polymorphisms (pN/pS) on the different mutations partitions observed in the $\mathrm{P}_{1}$ segment : all mutations observed in $\mathrm{HnO}$ (purple), all mutations observed in $\mathrm{Hn} 1 / \mathrm{Hn} 123$ (red), all mutations shared by $H$. pardalinus and $\mathrm{Hn} 1 / \mathrm{Hn} 123$ and not observed in $\mathrm{Hn0}$ (blue) and all mutations present uniquely in Hn1/Hn123 (yellow).

with a strong impact on individual survival in homozygotes. Interestingly, individuals with the Hn1/Hn123 genotype do not experience the deleterious effects of the $\mathrm{P}_{1}$ inversion (83,8\% survival), despite being effectively homozygous for this rearrangement (Fig. 4A). This may indicate that $\mathrm{Hn} 1$ and $\mathrm{Hn} 123$ harbor different deleterious variants within $\mathrm{P}_{1}$, for instance in the region surrounding the gene cortex which shows peaks of differentiation between those two haplotypes (Sup. Fig. S8), or that variants in $\mathrm{P}_{2}$ or $\mathrm{P}_{3}$ compensate for the deleterious effects of $P_{1}$.

Inversions have largely been considered for their value in preserving combinations of co-adapted alleles through suppressed recombination with ancestral chromatids, yet this also makes them prone to capturing deleterious mutations (19). Our results bring key insights into how the ecological and genetic components of balancing selection allow inversion polymorphisms to establish. Inversions in $\mathrm{H}$. $\mathrm{nu}$ mata show strongly positive dominant effects on adult survival through protection against predators via wing-pattern mimicry, which should lead to their rapid fixation (Fig. 4B, (16)). Yet we found that these inversions are also enriched in deleterious variation from their very formation, as well as from an accumulation of mutations owing to the reduction in recombination-driven purging. The expression of a recessive genetic load associated with inversions inevitably translates into negative frequency-dependent selection (21). The balancing selection acting on these inversions in $H$. numata thus results from their antagonistic ecological and genetic effects: positive selection and dominant effects on adult mimicry but negative frequency-dependent selection through recessive effects on viability (Fig 4B). The initial mutation load associated with the formation and introgression of inversion $\mathrm{P}_{1}$ likely initiated the balancing selection as soon as $P_{1}$ rose in frequency, and was further reinforced by the accumulation of deleterious mutations under low recombination. This led to the formation of haplotypes expressing net beneficial effects only when heterozygous.

Individuals carrying inversion $\mathrm{P}_{1}$ express disassortative mate preferences, which also balance inversion frequencies in the population (Fig 4B, (13)). Disassortative mating is likely to have evolved in response to the fitness costs associated with homozygous inversions, as selection may have favoured mate preferences minimizing the proportion of homozygous offspring (4). Disassortative mating further hampers the purging of deleterious variation located within the inversions. The initial capture of genetic load in the inversions thus triggered cascading ecological effects and led to the long-term persistence of polymorphism. The low recombination regime associated to inversions also favoured the insertion of transposons, increasing the size of the inverted haplotype. A similar pattern has also been observed in the Papaya neo sexchromosomes (22) and in the fire ant supergene (23), indicating that this initial increase in size due to accumulation of TE may be a general pattern in the early evolution of polymorphic chromosomes.

Our findings shed new light on the origin and evolution of complex polymorphisms controlled by supergenes and related architectures, such as sex-chromosomes. The buildup of antagonistic fitness effects found here is likely to be a general feature of the formation of inversion polymorphisms and their evolution through time. Therefore, the benefits of structural variants in terms of recombination suppression between ecologically adaptive traits may only explain why they are initially favoured, whereas their maintenance as polymorphisms may be driven by their initial and gradually accumulating mutation load. In summary, balancing selection may not be generated by extrinsic ecological factors, but by intrinsic features of the genetic architecture selected dur- 


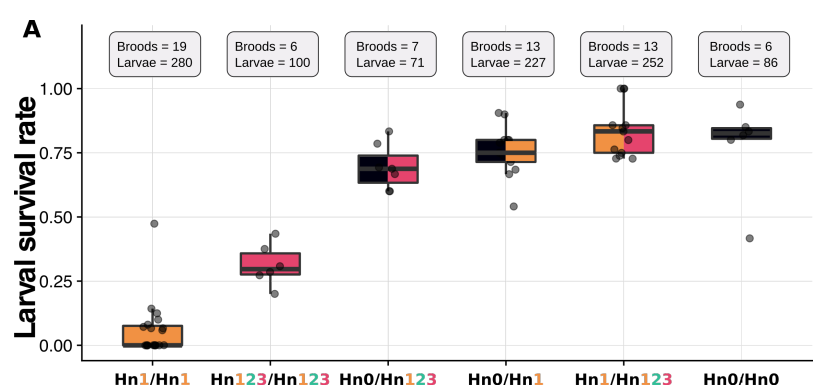

B

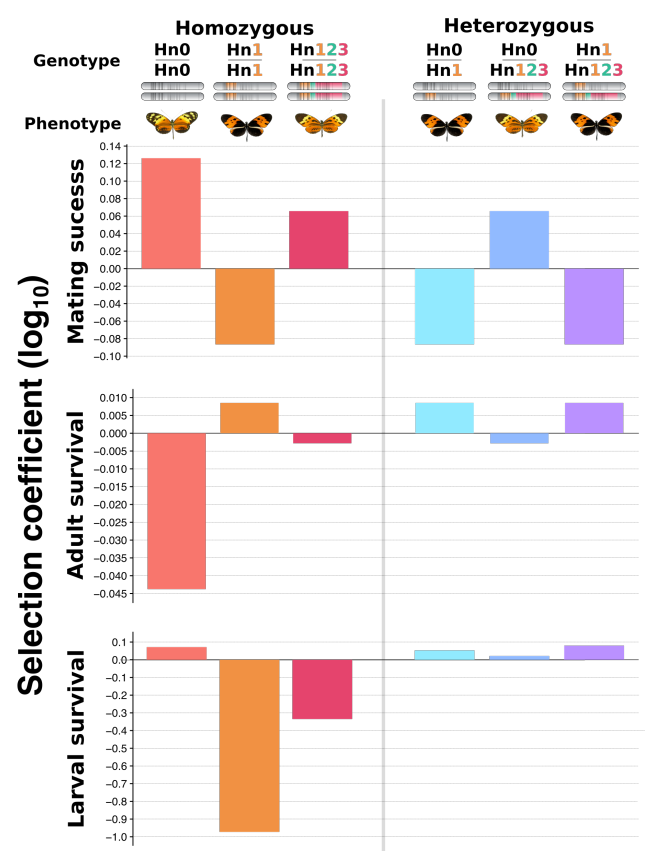

Fig. 4. Fitness variation associated with chromosomal inversions at the supergene in $H$. numata.

A. Larval survival rate for the different supergene genotypes. GLMM analysis confirmed that genotype was a significant predictor of survival $\left(\chi_{2}=459.776 ; \mathrm{df}=5\right.$; $p<0.001)$ while experimental cross design was unimportant $\left(\chi_{2}=0.8117 ; \mathrm{df}=2\right.$; $\mathrm{p}=0.666$ ), validating the joint analysis of all families and crosses. B. Variation in fitness components associated with supergene genotypes. Adult survival estimates are based on protection against predator. Selection coefficients were calculated relative to the population mean, and estimated in the $H$. numata population of Tarapoto, Peru. Predation and mating success data come from (16)) and (13)

ing the evolution of complex phenotypes. Taken together, these novel insights into the consequence of chromosomal rearrangements may explain why inversions are often found polymorphic and linked with complex phenotypes in nature. In a broader context, dissecting the opposing effects of suppressed recombination and how they determine the fate of chromosomal rearrangements may bring new light to our understanding of the variation in genome architecture across the tree of life.
Methods. Sampling and sequencing. To investigate the structure of the $\mathrm{P}$ supergene allele, we intercrossed wildcaught individuals in cages in order to obtain F2 (or later generation) autozygous individuals (i.e. with the two identical copies of the supergene allele). Samples were either conserved in $\mathrm{NaCl}$ saturated DMSO solution at $20^{\circ} \mathrm{C}$ or snap frozen alive in liquid nitrogen and conserved at $-80^{\circ} \mathrm{C}$ (Sup. Tab. S13). DNA was extracted from the whole butterfly bodies except the head with a protocol adapted from (24), with the following modification. Butterflies were ground in a frozen mortar with liquid nitrogen, $150 \mathrm{mg}$ of tissue powder was mixed with $900 \mu \mathrm{l}$ of preheated buffer and $6 \mu \mathrm{l}$ of RNaseA. Tube were incubated during 120 minutes at $50^{\circ} \mathrm{C}$ for lysis, and then at $-10^{\circ} \mathrm{C}$ for 10 minutes, with the addition of $300 \mu \mathrm{l}$ of Potassium acetate for the precipitation. One volume of binding buffer was added with $100 \mu$ of Serapure beads solution. 3 washing cycles were used and DNA was resuspended in $100 \mu$ l of EB buffer. Samples 35 and 36 were prepared using the NEBNExt FFPE DNA Repair MIX (NEB) . DNA fragment shorter than $20 \mathrm{~Kb}$ were removed for sample 35 and 36, and shorter than $40 \mathrm{~kb}$ for samples 26 and 28. 10x Chromium linked-read libraries of 10 autozygous individuals corresponding to 8 different morphs, as well as 2 wild-caught homozygous individuals, were prepared and $2 \times 150 \mathrm{bp}$ paired-end reads were sequenced using Illumina HiSeq 2500. Draft genomes were assembled using Supernova (v2.1.1, (25)) (Sup. Tab. S13).

Whole genome assemblies analysis. The assembled genomes were compared to the $H$. melpomene reference genome (Version 2.5) and to each other using BLAST (26), and LAST (27). Because for some specimens, the supergene was dispersed across multiple scaffolds, we used Ragout2 (28) to re-scaffold their supergene assembly, using as reference the four individual assemblies with the highest quality assembly statistics ( $\mathrm{n}^{\circ} 38,29,40$, and 26). Genome quality analysis was assessed with BUSCO using the insecta_odb9 database. MAKER (29) was used to annotate the genomes, using protein sequences obtained from the $H$. melpomene genome (v2.5, http://lepbase.org/) in combination with an $H$. numata transcriptome dataset (30). RepeatModeler (31) was used to identify unannotated TEs in the $12 \mathrm{H}$. numata genomes. Unknown repeat elements detected by RepeatModeler were compared by BLAST (26) (-evalue cut-off $\left.1 \mathrm{e}^{-10}\right)$ to a transposase database (Tpases080212) from (32). TE identified were merged with the Heliconius repeat database (Lavoie et al. 2013) and redundancy was filtered using CDHIT (REF) with a $80 \%$ identity threshold. RepeatMasker (31) was then used to annotate transposable elements and repeats using this combined database and results were parsed with scripts from https://github.com/4ureliek/ParsingRepeatMasker-Outputs.git.

Population Genomic Analysis. Whole genome re-sequence data from $H$. numata and other Heliconius species from (17) were used, as well as 37 new wild-caught $H$. numata specimens. For the latter samples, butterfly bodies were conserved in $\mathrm{NaCl}$ saturated DMSO solution at $-20^{\circ} \mathrm{C}$ and DNA was extracted using QIAGEN DNeasy blood and tissue kits ac- 
cording to the manufacturer's instructions with RNase treatment. Illumina Truseq paired-end whole genome libraries were prepared and $2 \times 100 \mathrm{bp}$ reads were sequenced on the Illumina HiSeq 2000 platform. Reads were mapped to the $H$. melpomene Hmel2 reference genome (33) using Stampy (version 1.0.28; (34)) with default settings except for the substitution rate which was set to 0.05 to allow for expected divergence from the reference. Alignment file manipulations were performed using SAMtools v0.1.3 (35). After mapping, duplicate reads were excluded using the MarkDuplicates tool in Picard (v1.1125; http://broadinstitute.github.io/picard) and local indel realignment using IndelRealigner was performed with GATK(v3.5; (36)). Invariant and polymorphic sites were called with GATK HaplotypeCaller, with options min_base_quality_score 25 -min_mapping_quality_score 25 -stand_emit_conf 20 -heterozygosity 0.015 . VCF data were processed using bcftools (37). PCA analyses were computed with the SNPRelate R package (38), using 5kb windows. Using Phylobayes (39), on 5kb sliding windows, we estimated 1) the most recent coalescence event between $\mathrm{Hn} 0+\mathrm{Hn} 1$ and Hn123, which corresponds to age of the last recombination between $\mathrm{Hn} 0+\mathrm{Hn} 1$ and $\mathrm{Hn} 123$, and 2) the time to the most recent common ancestor (TMRCA) of all Hn123 haplotypes. This provides respectively the upper (1) and the lower (2) bounds of the date of the inversion event (Sup Fig. S7). In order to compute the Fst and standard population genetic analyses, we manually curated the phasing of heterozygous individuals since computational phasing packages such as SHAPEIT or BEAGLE were found to introduce frequent phase switch errors. For each heterozygous SNP in inversion regions, if one and only one of the two alleles is observed in more than $80 \%$ of individuals without inversions ( $\mathrm{Hn} 0)$, this allele is considered as being on the haplotype 1, the other being on haplotype 2. For SNPs which did not fit this criterion, each allele was placed randomly on one of the two haplotypes.

Deleterious mutation accumulation. SnpEff (40) with default was used to annotate the $H$. numata SNPs using the $H$. melpomene reference genome annotation. We computed the ratio of synonymous and non-synonymous variants $(\mathrm{pN} / \mathrm{pS})$, the rate of synonymous and non-synonymous substitution $(\mathrm{dN} / \mathrm{dS})$ compared to H. melpomene, and the direction of selection with $\mathrm{DoS}=\mathrm{Dn} /(\mathrm{Dn}+\mathrm{Ds}) \mathrm{Pn} /(\mathrm{Pn}+\mathrm{Ps})(20)$, using all individuals, or only those homozygous for a given inversion type, for every genes larger $5 \mathrm{~kb}$ (to ensure there is a several SNP within each gene). Whole genome distribution was computed on $500 \mathrm{~kb}$ non-overlapping sliding windows.

Fitness Assay. H. numata specimens used for the fitness analyses originated the Tarapoto valley, San Martin, Peru. Brood designs are illustrated in Sup. Fig. 10. First, F1 $\mathrm{P}$ heterozygotes butterflies were generated by crossing F0 wild males to captive bred virgin females. Unrelated F1 male-female pairs were then selected for their P genotype and hand paired to generate an F2 progeny. We specifically designed these crosses to generate a F2 progeny containing both homozygotes and heterozygotes, within a single family. Larvae were monitored twice a day to assess survival or mortality. Upon death or butterfly emergence, individuals were stored in $96^{\circ}$ ethanol until genotyping. We generated a total of 486 F2 progeny from 6 independent replicate of broods for the $\mathrm{F} 1 \mathrm{Hn} 0 / \mathrm{Hn} 1 \times \mathrm{Hn} 0 / \mathrm{Hn} 1$ cross, 504 F2 progeny from 6 brood of the F1 Hn1/Hn123 x Hn1/Hn123 cross and $454 \mathrm{~F} 2$ progeny from 7 broods of the F1 Hn1/Hn123 $\mathrm{x} \mathrm{Hn} 0 / \mathrm{Hn} 1$ cross. Supergene genotypes was assessed using (13) methodology. Briefly, the amplification of the Heliconius numata orthologue of HM00025 (cortex) (Genbank accension FP236845.2), included in the supergene $P$ enables to discriminate between the distinct supergene haplotype by PCR product size: Hn1 ( 1200bp), Hn123 ( 800bp) and $\mathrm{Hn} 0(\sim 600$ bp). 1,016 F2 progeny could be genotyped. For each of the 19 broods, we used a Chi-squared test of independence to assess variation in survival between the different genotypes of the F2 progeny. When significant, the FreemanTukey deviates (FT) was compared to an alpha $=0.05$ criterion, and corrected for multiple comparisons using the Bonferroni correction. To compare genotype survival between families and crosses we performed generalized linear mixed models analysis followed by a Tukey's HSD post-hoc test (package "lme4" (41); in R version 3.1.3, (42)), with the survival of an individual with a given genotype as the response variable (binomial response with logit link). The significance of the predictors was tested using likelihood ratio tests. The genotype was a covariate predictor, crosses was a fixed effect and family identity as a random effect to control for nonindependence of measures. Plots were created with ggplot2 (43).

\section{ACKNOWLEDGEMENTS}

We thank Emmanuelle d'Alençon and Marie-Pierre Dubois for their help in the lab, Thomas Aubier for being a DNA extraction wizard, Melanie McClure, Mario Tuatama, Ronald Mori-Pezo for their help during field work, Patrice David for his careful and critical reading of the manuscript, Konrad Lhose, Dominik Laetsch, Benoit Nabolz, Pierre-Alexandre Gagnaire, Mathieu Gauthier, Claire Lemaitre, Fabrice Legeai and Anna-Sophie Fiston-Lavier for insightful discussions. We thank the Peruvian government for providing the necessary research permits (236-2012-AGDGFFS-DGEFFS, 201-2013-MINAGRI-DGFFS/DGEFFS and 002-2015-SERFORDGGSPFFS). This research was supported by Agence Nationale de la Recherche (ANR) grants ANR-12-JSV7-0005 and ANR-18-CE02-0019-01 and European Research Council grant ERC-StG-243179 to MJ and by fellowships from the Natural Sciences and Engineering Research Council of Canada and a Marie SklodowskaCurie fellowship (FITINV, N 655857) to MC. This project benefited from the Montpellier Bioinformatics Biodiversity platform supported by the LabEx CeMEB, ANR "Investissements d'avenir" program ANR-10-LABX-04-01. MGX acknowledges financial support from France Génomique National infrastructure, funded as part of ANR "Investissement d'avenir" program ANR-10-INBS-09.

\section{AUTHOR CONTRIBUTIONS}

P.J., M.C., and M.J. designed the study. P.J., M.C., A.W., and M.J. wrote the paper. P.J., A.W., and M.J. generated the genomic data. M.C., H.B and V.L. generated the RNAseq data. P.J. performed the genomic analyses with input from A.W.. M.C. managed butterfly rearing and performed fitness assays. H.P. performed whole genomes sequencing. All authors contributed to editing the manuscript.

\section{COMPETING FINANCIAL INTERESTS}

The authors declare no competing interests

\section{Bibliography}

1. John Wang, Yannick Wurm, Mingkwan Nipitwattanaphon, Oksana Riba-Grognuz, Yu-Ching Huang, DeWayne Shoemaker, and Laurent Keller. A Y-like social chromosome causes alternative colony organization in fire ants. Nature, 493(7434):664-668, January 2013. ISSN 1476-4687. doi: 10.1038/nature11832.

2. Sangeet Lamichhaney, Guangyi Fan, Fredrik Widemo, Ulrika Gunnarsson, Doreen Schwochow Thalmann, Marc P. Hoeppner, Susanne Kerje, Ulla Gustafson, Chengcheng Shi, He Zhang, Wenbin Chen, Xinming Liang, Leihuan Huang, Jiahao Wang, Enjing Liang, Qiong Wu, Simon Ming-Yuen Lee, Xun Xu, Jacob Höglund, Xin Liu, and Leif Andersson. Structural genomic changes underlie alternative reproductive strategies in the ruff (Philo- 
bioRxiv preprint doi: https://doi.org/10.1101/736504; this version posted August 15,2019 . The copyright holder for this preprint (which was not certified by peer review) is the author/funder, who has granted bioRxiv a license to display the preprint in perpetuity. It is made available under aCC-BY-NC-ND 4.0 International license.

machus pugnax). Nature Genetics, 48(1):84-88, January 2016. ISSN 1546-1718. doi: 10.1038/ng.3430.

3. Clemens Küpper, Michael Stocks, Judith E. Risse, Natalie dos Remedios, Lindsay L. Farrell, Susan B. McRae, Tawna C. Morgan, Natalia Karlionova, Pavel Pinchuk, Yvonne I. Verkuil, Alexander S. Kitaysky, John C. Wingfield, Theunis Piersma, Kai Zeng, Jon Slate, Mark Blaxter, David B. Lank, and Terry Burke. A supergene determines highly divergent male reproductive morphs in the ruff. Nature Genetics, 48(1):79-83, January 2016. ISSN 15461718. doi: $10.1038 /$ ng. 3443 .

4. Elaina M. Tuttle, Alan O. Bergland, Marisa L. Korody, Michael S. Brewer, Daniel J. Newhouse, Patrick Minx, Maria Stager, Adam Betuel, Zachary A. Cheviron, Wesley C. Warren, Rusty A. Gonser, and Christopher N. Balakrishnan. Divergence and Functional Degradation of a Sex Chromosome-like Supergene. Current Biology, 26(3):344-350, February 2016. ISSN 0960-9822. doi: 10.1016/j.cub.2015.11.069.

5. Mathieu Joron, Lise Frezal, Robert T. Jones, Nicola L. Chamberlain, Siu F. Lee, Christoph R. Haag, Annabel Whibley, Michel Becuwe, Simon W. Baxter, Laura Ferguson, Paul A. Wilkinson, Camilo Salazar, Claire Davidson, Richard Clark, Michael A. Quail, Helen Beasley, Rebecca Glithero, Christine Lloyd, Sarah Sims, Matthew C. Jones, Jane Rogers, Chris D. Jiggins, and Richard H. ffrench Constant. Chromosomal rearrangements maintain a polymorphic supergene controlling butterfly mimicry. Nature, 477(7363):203-206, September 2011. ISSN 1476-4687. doi: 10.1038/nature10341.

6. K. Kunte, W. Zhang, A. Tenger-Trolander, D. H. Palmer, A. Martin, R. D. Reed, S. P. Mullen, and M. R. Kronforst. doublesex is a mimicry supergene. Nature, 507(7491):229-232, March 2014. ISSN 1476-4687. doi: 10.1038/nature13112.

7. Jinhong Li, Jonathan M. Cocker, Jonathan Wright, Margaret A. Webster, Mark McMullan, Sarah Dyer, David Swarbreck, Mario Caccamo, Cock van Oosterhout, and Philip M. Gilmartin. Genetic architecture and evolution of the $S$ locus supergene in Primula vulgaris. Nature Plants, 2(12):16188, December 2016. ISSN 2055-0278. doi: 10.1038/nplants.2016. 188.

8. R. A. Fisher. The genetical theory of natural selection. The genetical theory of natural selection. Clarendon Press, Oxford, England, 1930. doi: 10.5962/bhl.title.27468.

9. E.B. Ford. Genetic Polymorphism. Faber \& Faber: London, 1965.

10. D. Charlesworth and B. Charlesworth. Theoretical genetics of Batesian mimicry II. Evolution of supergenes. Journal of Theoretical Biology, 55(2):305-324, December 1975. ISSN 0022 5193. doi: 10.1016/s0022-5193(75)80082-8.

11. Michael Kopp and Joachim Hermisson. The evolution of genetic architecture under frequency-dependent disruptive selection. Evolution; International Journal of Organic EvoIution, 60(8):1537-1550, August 2006. ISSN 0014-3820.

12. Jessica K. Abbott, Anna K. Nordén, and Bengt Hansson. Sex chromosome evolution: historical insights and future perspectives. Proceedings. Biological Sciences, 284(1854), May 2017. ISSN 1471-2954. doi: 10.1098/rspb.2016.2806.

13. Mathieu Chouteau, Violaine Llaurens, Florence Piron-Prunier, and Mathieu Joron. Polymorphism at a mimicry supergene maintained by opposing frequency-dependent selection pressures. Proceedings of the National Academy of Sciences, page 201702482, June 2017. ISSN 0027-8424, 1091-6490. doi: 10.1073/pnas.1702482114.

14. B. Sinervo and C. M. Lively. The rock-paper-scissors game and the evolution of alternative male strategies. Nature, 380(6571):240-243, March 1996. ISSN 1476-4687. doi: 10.1038/ $380240 \mathrm{a} 0$.

15. Mark R Christie, Gordon G McNickle, Rod A French, and Michael S Blouin. Life history variation is maintained by fitness trade-offs and negative frequency-dependent selection. Proceedings of the National Academy of Sciences, 115(17):4441-4446, 2018.

16. Mathieu Chouteau, Mónica Arias, and Mathieu Joron. Warning signals are under positive frequency-dependent selection in nature. Proceedings of the National Academy of Sciences, 113(8):2164-2169, February 2016. ISSN 0027-8424, 1091-6490. doi: 10.1073/pnas.1519216113.

17. Paul Jay, Annabel Whibley, Lise Frézal, María Ángeles Rodríguez de Cara, Reuben W. Nowell, James Mallet, Kanchon K. Dasmahapatra, and Mathieu Joron. Supergene Evolution Triggered by the Introgression of a Chromosomal Inversion. Current Biology, 28(11):18391845.e3, June 2018. ISSN 0960-9822. doi: 10.1016/j.cub.2018.04.072.

18. Mark Kirkpatrick. How and Why Chromosome Inversions Evolve. PLoS Biology, 8(9), September 2010. ISSN 1544-9173. doi: 10.1371/journal.pbio.1000501.

19. Rui Faria, Kerstin Johannesson, Roger K. Butlin, and Anja M. Westram. Evolving Inversions. Trends in Ecology \& Evolution, 34(3):239-248, March 2019. ISSN 0169-5347. doi: 10.1016/ j.tree.2018.12.005.

20. Nina Stoletzki and Adam Eyre-Walker. Estimation of the neutrality index. Molecular Biology and Evolution, 28(1):63-70, January 2011. ISSN 1537-1719. doi: 10.1093/molbev/msq249.

21. Violaine Llaurens, Annabel Whibley, and Mathieu Joron. Genetic architecture and balancing selection: the life and death of differentiated variants. Molecular Ecology, 26(9):2430-2448, May 2017. ISSN 0962-1083. doi: 10.1111/mec.14051.

22. Jianping Wang, Jong-Kuk Na, Qingyi Yu, Andrea R. Gschwend, Jennifer Han, Fanchang Zeng, Rishi Aryal, Robert VanBuren, Jan E. Murray, Wenli Zhang, Rafael Navajas-Pérez, F. Alex Feltus, Cornelia Lemke, Eric J. Tong, Cuixia Chen, Ching Man Wai, Ratnesh Singh, Ming-Li Wang, Xiang Jia Min, Maqsudul Alam, Deborah Charlesworth, Paul H. Moore, Jiming Jiang, Andrew H. Paterson, and Ray Ming. Sequencing papaya $X$ and $Y h$ chromosomes reveals molecular basis of incipient sex chromosome evolution. Proceedings of the National Academy of Sciences, 109(34):13710-13715, August 2012. ISSN 0027-8424, 1091-6490. doi: 10.1073/pnas.1207833109.

23. Eckart Stolle, Rodrigo Pracana, Philip Howard, Carolina I. Paris, Susan J. Brown, Claudia Castillo-Carrillo, Stephen J. Rossiter, and Yannick Wurm. Degenerative Expansion of a Young Supergene. Molecular Biology and Evolution, 36(3):553-561, March 2019. ISSN 0737-4038. doi: 10.1093/molbev/msy236.

24. Baptiste Mayjonade, Jérôme Gouzy, Cécile Donnadieu, Nicolas Pouilly, William Marande, Caroline Callot, Nicolas Langlade, and Stéphane Muños. Extraction of high-molecularweight genomic DNA for long-read sequencing of single molecules. BioTechniques, 61(4): 203-205, 2016. ISSN 1940-9818. doi: 10.2144/000114460.

25. Neil I. Weisenfeld, Vijay Kumar, Preyas Shah, Deanna M. Church, and David B. Jaffe. Direct determination of diploid genome sequences. Genome Research, 27(5):757-767, 2017.
ISSN 1549-5469. doi: 10.1101/gr.214874.116.

26. S. F. Altschul, W. Gish, W. Miller, E. W. Myers, and D. J. Lipman. Basic local alignment search tool. Journal of Molecular Biology, 215(3):403-410, October 1990. ISSN 00222836. doi: 10.1016/S0022-2836(05)80360-2.

27. Szymon M. Kietbasa, Raymond Wan, Kengo Sato, Paul Horton, and Martin C. Frith. Adaptive seeds tame genomic sequence comparison. Genome Research, 21(3):487-493, January 2011. ISSN 1088-9051, 1549-5469. doi: 10.1101/gr.113985.110.

28. Mikhail Kolmogorov, Joel Armstrong, Brian J. Raney, lan Streeter, Matthew Dunn, Fengtang Yang, Duncan Odom, Paul Flicek, Thomas M. Keane, David Thybert, Benedict Paten, and Son Pham. Chromosome assembly of large and complex genomes using multiple references. Genome Research, October 2018. ISSN 1088-9051, 1549-5469. doi: 10.1101/gr.236273.118.

29. Brandi L. Cantarel, Ian Korf, Sofia M.C. Robb, Genis Parra, Eric Ross, Barry Moore, Carson Holt, Alejandro Sánchez Alvarado, and Mark Yandell. MAKER: An easy-to-use annotation pipeline designed for emerging model organism genomes. Genome Research, 18(1):188196, January 2008. ISSN 1088-9051. doi: 10.1101/gr.6743907.

30. Suzanne V Saenko, Mathieu Chouteau, Florence Piron-Prunier, Corinne Blugeon, Mathieu Joron, and Violaine Llaurens. Unravelling the genes forming the wing pattern supergene in the polymorphic butterfly heliconius numata. EvoDevo, 10(1):1-12, 2019.

31. Hubley R \& Green P. Smit, AFA. RepeatMasker Open-4.0. 2013-2015.

32. Michael S. Campbell, MeiYee Law, Carson Holt, Joshua C. Stein, Gaurav D. Moghe, David E. Hufnagel, Jikai Lei, Rujira Achawanantakun, Dian Jiao, Carolyn J. Lawrence, Doreen Ware, Shin-Han Shiu, Kevin L. Childs, Yanni Sun, Ning Jiang, and Mark Yandell. MAKER-P: a tool kit for the rapid creation, management, and quality control of plant genome annotations. Plant Physiology, 164(2):513-524, February 2014. ISSN 1532-2548. doi: 10.1104/pp.113.230144.

33. John W. Davey, Mathieu Chouteau, Sarah L. Barker, Luana Maroja, Simon W. Baxter, Fraser Simpson, Richard M. Merrill, Mathieu Joron, James Mallet, Kanchon K. Dasmahapatra, and Chris D. Jiggins. Major Improvements to the Heliconius melpomene Genome Assembly Used to Confirm 10 Chromosome Fusion Events in 6 Million Years of Butterfly Evolution. G3: Genes, Genomes, Genetics, 6(3):695-708, March 2016. ISSN 2160-1836. doi: 10. $1534 / \mathrm{g} 3.115 .023655$.

34. Gerton Lunter and Martin Goodson. Stampy: a statistical algorithm for sensitive and fast mapping of Illumina sequence reads. Genome Research, 21(6):936-939, June 2011. ISSN 1549-5469. doi: 10.1101/gr.111120.110.

35. Heng Li, Bob Handsaker, Alec Wysoker, Tim Fennell, Jue Ruan, Nils Homer, Gabor Marth, Goncalo Abecasis, and Richard Durbin. The Sequence Alignment/Map format and SAMtools. Bioinformatics, 25(16):2078-2079, August 2009. ISSN 1367-4803. doi: 10.1093/bioinformatics/btp352.

36. M.A. DePristo, E. Banks, R.E. Poplin, K.V. Garimella, J.R. Maguire, C. Hartl, A.A. Philippakis, G. del Angel, M.A Rivas, M. Hanna, A. McKenna, T.J. Fennell, A.M. Kernytsky, A.Y. Sivachenko, K. Cibulskis, S.B. Gabriel, D. Altshuler, and M.J. Daly. A framework for variation discovery and genotyping using next-generation DNA sequencing data. Nature genetics, 43 (5):491-498, May 2011. ISSN 1061-4036. doi: 10.1038/ng.806.

37. Petr Danecek, Adam Auton, Goncalo Abecasis, Cornelis A. Albers, Eric Banks, Mark A DePristo, Robert E. Handsaker, Gerton Lunter, Gabor T. Marth, Stephen T. Sherry, Gilean McVean, and Richard Durbin. The variant call format and VCFtools. Bioinformatics, 27(15): 2156-2158, August 2011. ISSN 1367-4803. doi: 10.1093/bioinformatics/btr330.

38. Xiuwen Zheng, David Levine, Jess Shen, Stephanie M. Gogarten, Cathy Laurie, and Bruce S. Weir. A high-performance computing toolset for relatedness and principal component analysis of SNP data. Bioinformatics, 28(24):3326-3328, December 2012. ISSN 1367-4803. doi: 10.1093/bioinformatics/bts606.

39. Nicolas Lartillot and Hervé Philippe. A Bayesian mixture model for across-site heterogeneities in the amino-acid replacement process. Molecular Biology and Evolution, 21(6): 1095-1109, June 2004. ISSN 0737-4038. doi: 10.1093/molbev/msh112.

40. P. Cingolani, A. Platts, M. Coon, T. Nguyen, L. Wang, S.J. Land, X. Lu, and D.M. Ruden. A program for annotating and predicting the effects of single nucleotide polymorphisms, snpeff: Snps in the genome of drosophila melanogaster strain w1118; iso-2; iso-3. Fly, 6 (2):80-92, 2012.

41. Douglas Bates, Martin Mächler, Ben Bolker, and Steve Walker. Fitting Linear Mixed-Effects Models Using Ime4. Journal of Statistical Software, 67(1):1-48, October 2015. ISSN 15487660. doi: 10.18637/jss.v067.i01.

42. R Core Team. R: A language and environment for statistical computing., 2013.

43. H. Wickham. ggplot2: Elegant Graphics for Data Analysis. Springer-verlag new york edition, 2016. 
bioRxiv preprint doi: https://doi.org/10.1101/736504; this version posted August 15, 2019. The copyright holder for this preprint (which was not certified by peer review) is the author/funder, who has granted bioRxiv a license to display the preprint in perpetuity. It is made available under aCC-BY-NC-ND 4.0 International license.

\section{Supplementary Note 1: Figures}

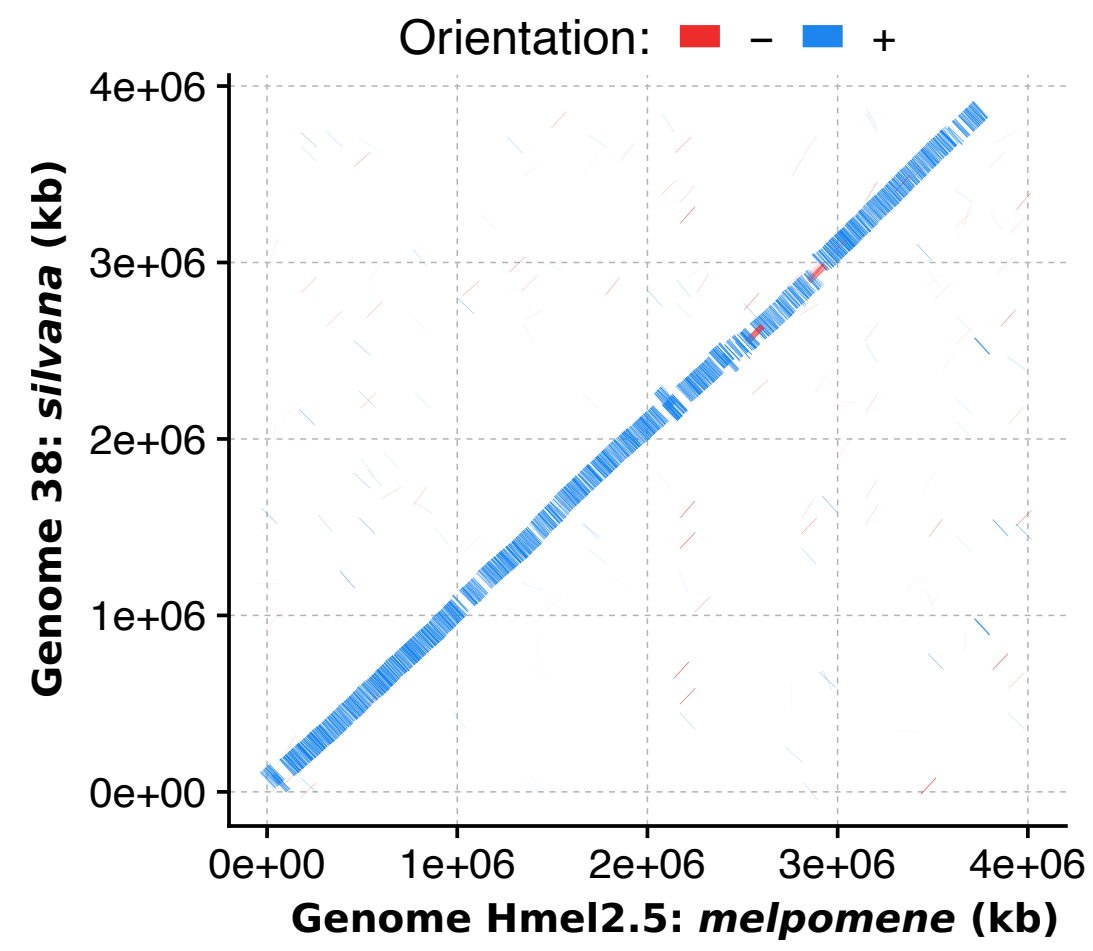

Fig. S1. Alignment of genome assemblies of $\boldsymbol{H}$. numata silvana $(\mathrm{Hn} 0$, genome 38$)$ and the $\boldsymbol{H}$. melpomene reference genome (Hmel2.5) focused on the region of the supergene on chromosome 15

No major chromosomal rearrangements are observed between $\mathrm{Hn} 0$ and Heliconius melpomene on chromosome 15.
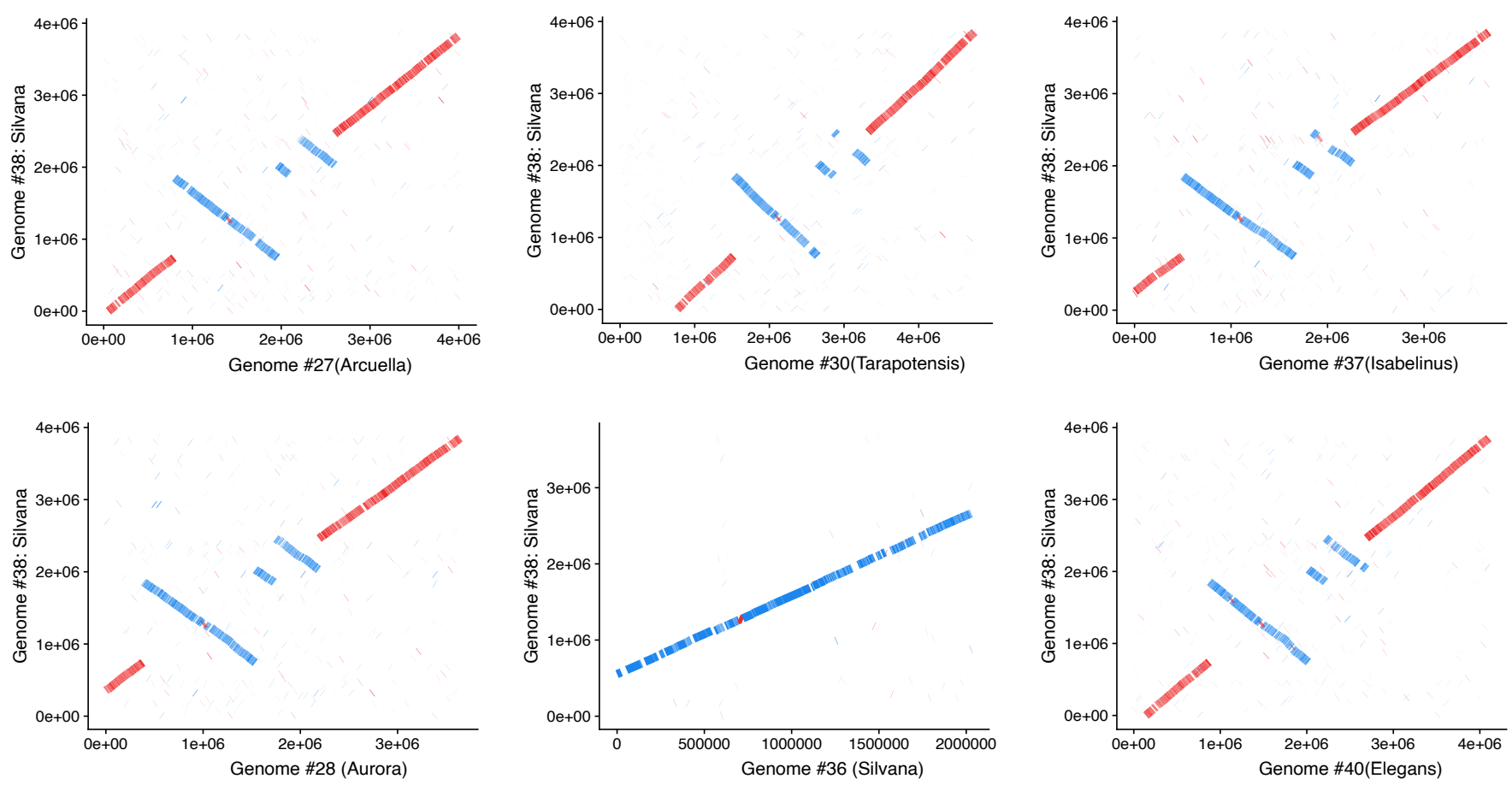

Fig. S2. Alignment of the supergene region of genome 38 (H. n. silvana) against other $H$. numata genome assemblies. 
bioRxiv preprint doi: https://doi.org/10.1101/736504; this version posted August 15, 2019. The copyright holder for this preprint (which was not certified by peer review) is the author/funder, who has granted bioRxiv a license to display the preprint in perpetuity. It is made available under aCC-BY-NC-ND 4.0 International license.

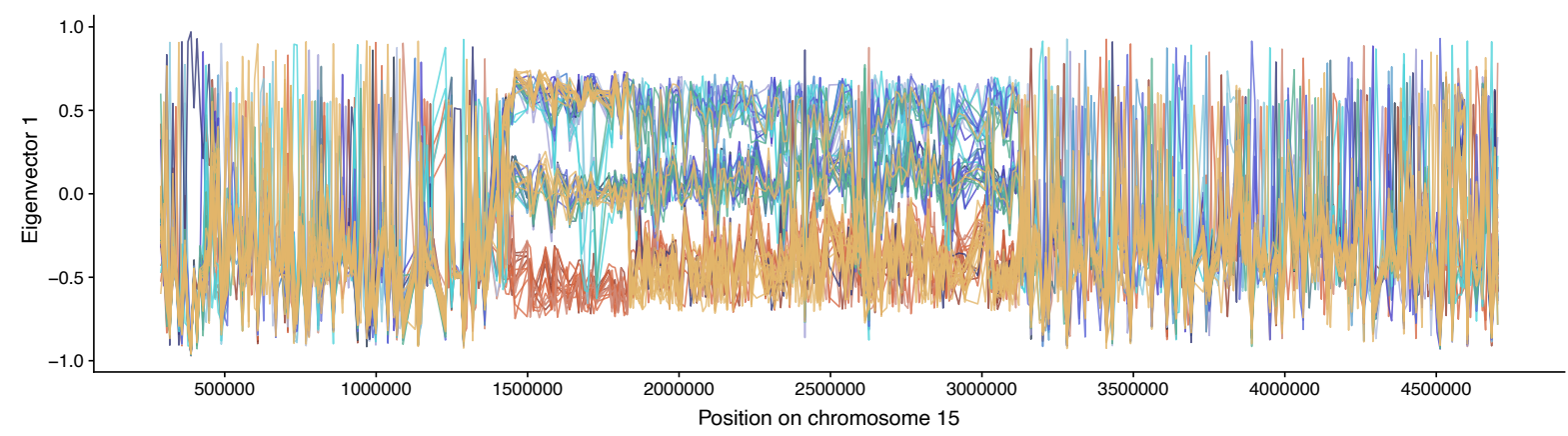

Morph

- Lyrcaeus

- Lutea

- Isabelinus
- Euphrasius

- Euphone

- Aurora

- Arcuella

Position on chromosome 15

Fig. S3. Sliding window PCA computed along the supergene for all specimens.

Computed on $5 \mathrm{~kb}$ sliding windows. Each line represents the position of a specimen on the first axis of the PCA along chromosome 15. See Sup. Fig. 4S for summary PCAs, not computed on sliding windows but on the whole regions. 
bioRxiv preprint doi: https://doi.org/10.1101/736504; this version posted August 15,2019 . The copyright holder for this preprint (which was not certified by peer review) is the author/funder, who has granted bioRxiv a license to display the preprint in perpetuity. It is made available under aCC-BY-NC-ND 4.0 International license.

\section{Morphs:}
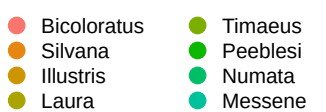

Lyrcaeus

Lutea

$\begin{array}{ll}\text { Isabelinus } & \text { Arcuella } \\ \text { Euphrasius } & \text { Tarapotensis }\end{array}$

Euphone

- Aurora

- Messene
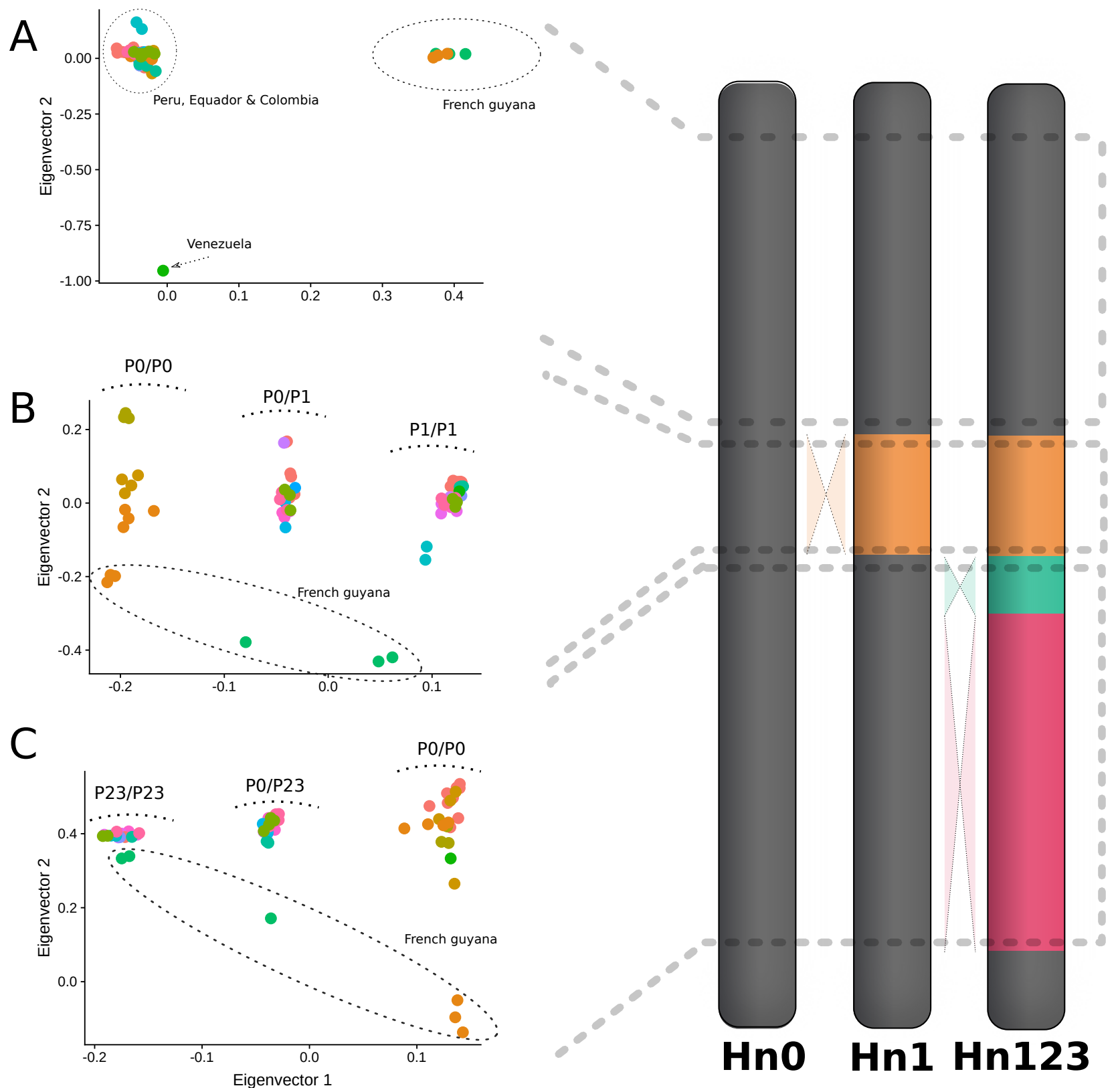

Fig. S4. PCA computed on SNPs, on the inversion segments and outside the supergene, for all specimens.

Each dot represents the position of a specimen on the PCA two first axis. A. PCA computed on SNPs on the chromosome 15 but not within the supergene region. The PCA reflect the geographic structure of the dataset. B. PCA computed on SNPs on $\mathrm{P}_{1}$ segment. The first axis of the PCA reflects individual genotypes for the inversion : homozygote for the ancestral gene order (P0/P0), Homozygote for the inversion (P1/P1), or heterozygote (P0/P1). The second axis of the PCA reflects the geographic structure of the dataset. C. PCA computed on SNPs on $\mathrm{P}_{2}+\mathrm{P} 3$ segment. The first axis of the PCA reflects individual genotypes for the two inversions : homozygote for the ancestral gene order (P0/P0), Homozygote for the two inversions (P23/P23), or heterozygote (P0/P23); the second axis of the PCA reflects the geographic structure of the dataset. 
bioRxiv preprint doi: https://doi.org/10.1101/736504; this version posted August 15,2019 . The copyright holder for this preprint (which was not certified by peer review) is the author/funder, who has granted bioRxiv a license to display the preprint in perpetuity. It is made available under aCC-BY-NC-ND 4.0 International license.

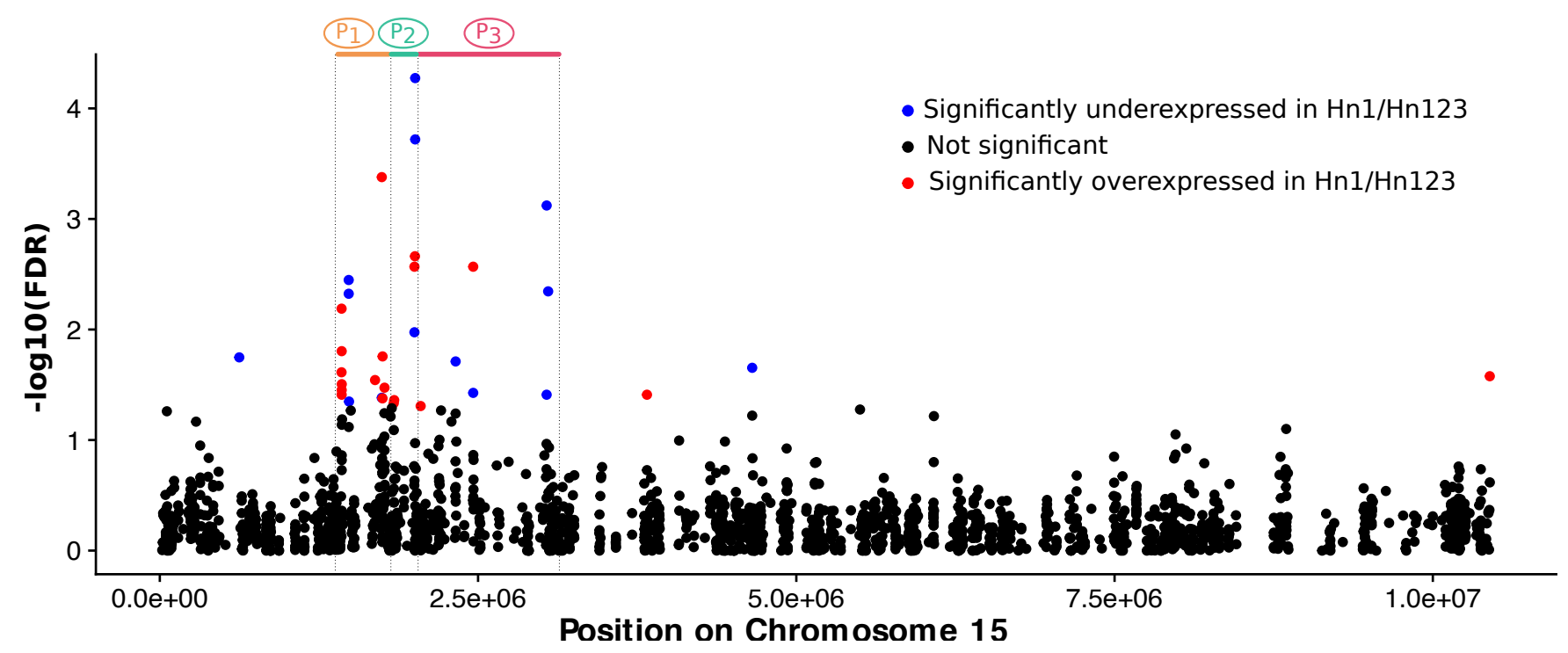

Fig. S5. Differential gene expression across the chromosome 15

Expression difference in early pupal (24h) wing discs between $\mathrm{HnO}$ and $\mathrm{Hn} 1 / \mathrm{Hn} 123$. RNAseq data from (1) were reanalysed using the EdgeR R package (2)). The -log10 of the false discovery rate is plotted along the chromosome 15 , with each dot representing a different transcript, and reveal that genes within the inversion segments are differentially expressed between $\mathrm{Hn} 0$ and $\mathrm{Hn} 1-\mathrm{Hn} 123$. 
bioRxiv preprint doi: https://doi.org/10.1101/736504; this version posted August 15, 2019. The copyright holder for this preprint (which was not certified by peer review) is the author/funder, who has granted bioRxiv a license to display the preprint in perpetuity. It is made available under aCC-BY-NC-ND 4.0 International license.

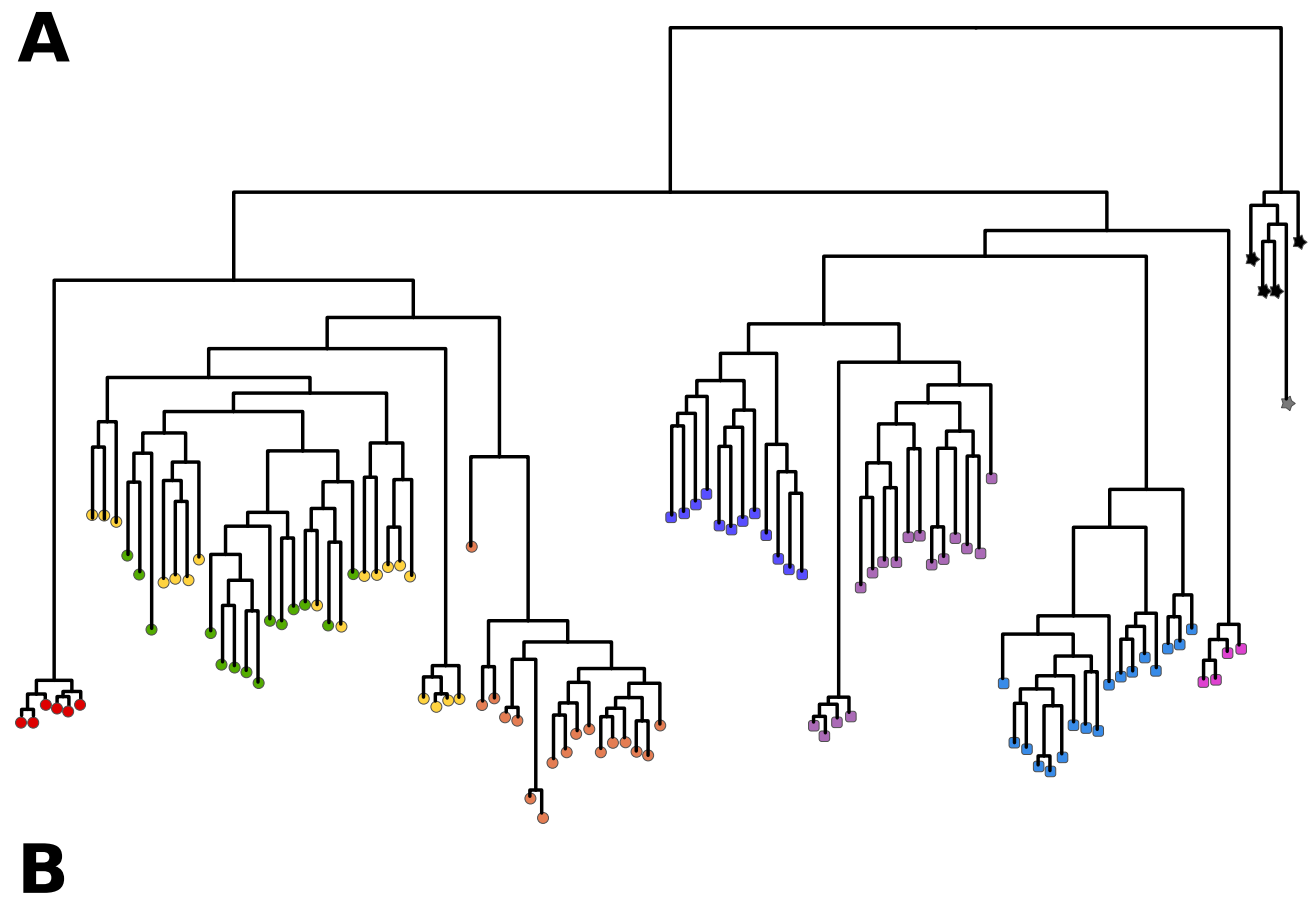

H. ethilla
H. hecale
H. pardalinus
H. elevatus
H. numata without inversion
H. numata with inversion $P_{1+2+3}$
- H. numata with inversion $P_{1}$
H. ismenius
H. cydno
H. melpomene

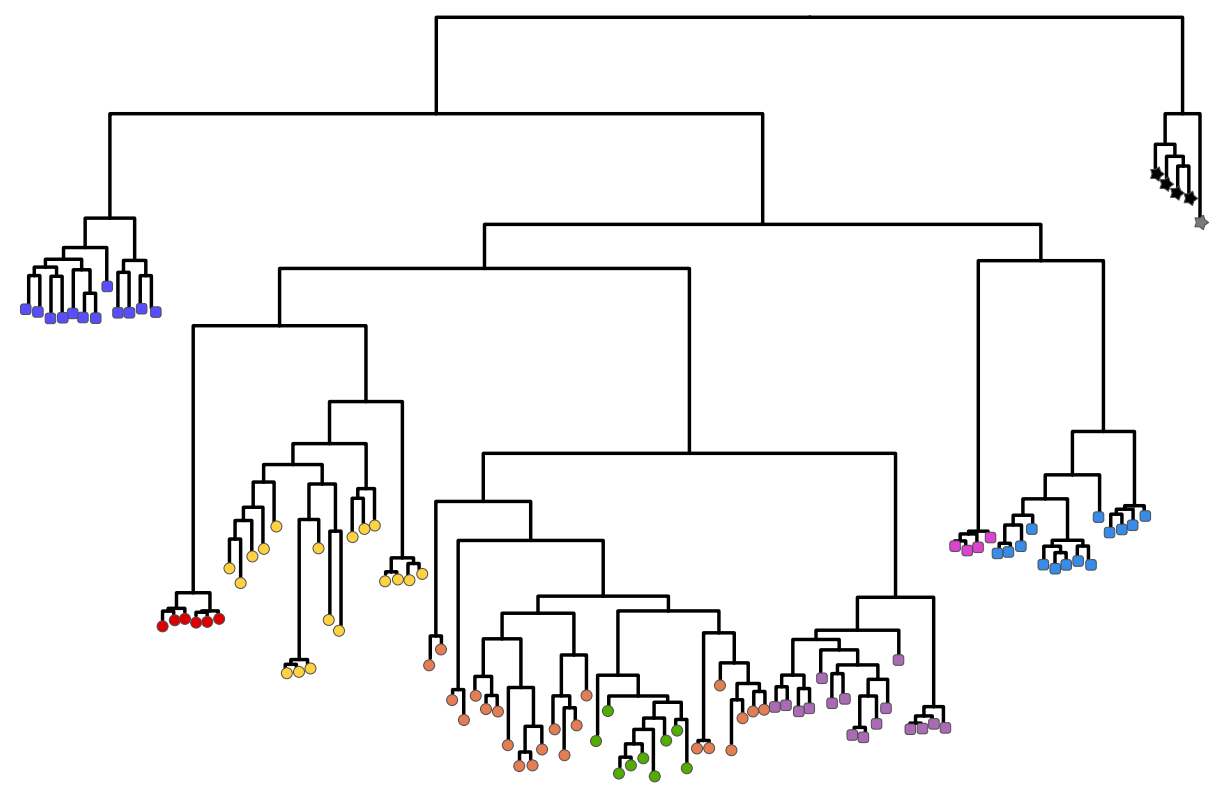

Fig. S6. Phylogenies of the silvaniform clade with $H$. cydno and $H$. melpomene as outgroups, using the genomic segments orthologous to $P_{1}, P_{2}$ and $P_{3}$ in $H$. numata.

Phylogenies computed with RAXML (3) using the GTRCAT model and only individuals homozygous for the inversions or the standard arrangement. A. Phylogeny of segments orthologous to $P_{2}$ and $P_{3}$. This shows the unique origin of the $P_{2}$ and $P_{3}$ inversions within $H$. numata. B. Phylogeny of segments orthologous to $P_{1}$. This show the introgression of $P_{1}$ from $H$. pardalinus into $H$. numata. Incongruent position of $H$. elevatus, $H$. hecale and $H$. ethilla result from incomplete lineage sorting at the clade level around the gene cortex and to gene flow among species of the clade (especially an introgression between $H$. elevatus and $H$. melpomene) (4). 


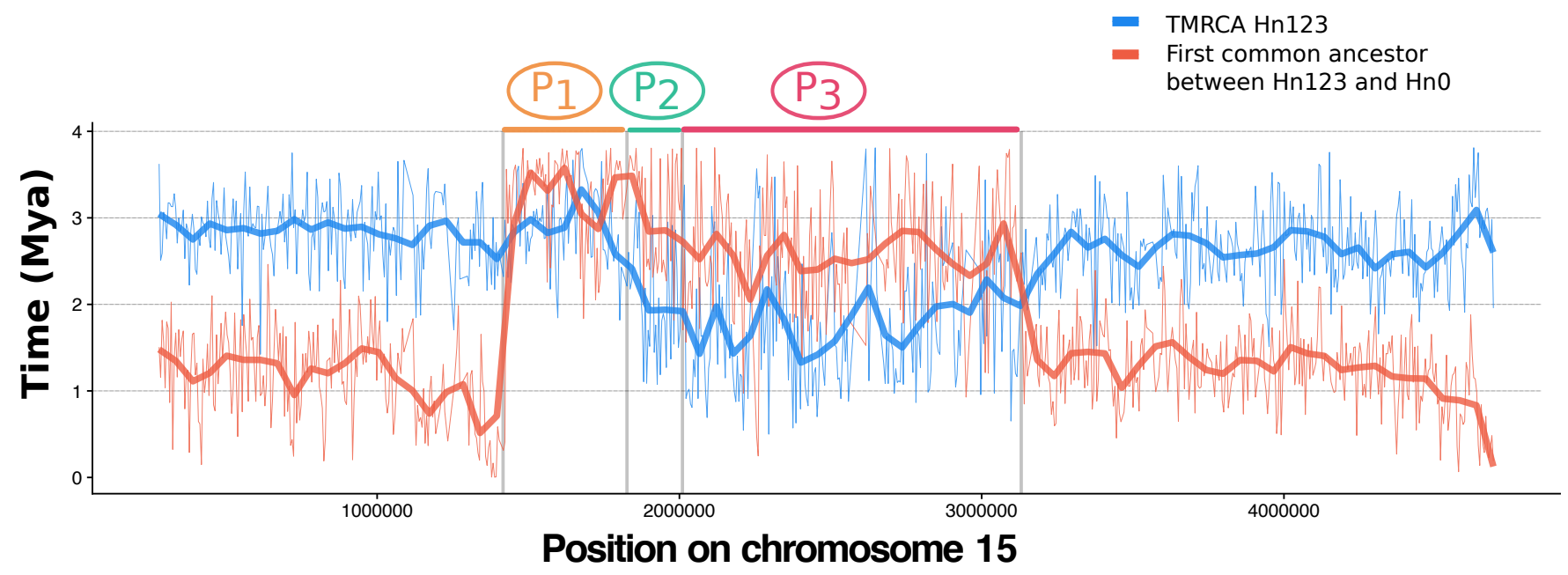

Fig. S7. Analysis of divergence times between $\mathrm{Hn} 123$ and $\mathrm{Hn} 0$ along the chromosome 15.

Divergence time estimates computed with Phylobayes on $5 \mathrm{~kb}$ sliding windows. Bold red and blue lines represent the LOESS smoothing (span $=0.05$ ) of the raw data (thin lines) and give the upper and lower bound of the times inversions $P_{2}$ and $P_{3}$ occurred. This supports the formation of $P$ supergene by the stepwise accretion of $P_{1}, P_{2}$ and $P_{3}$

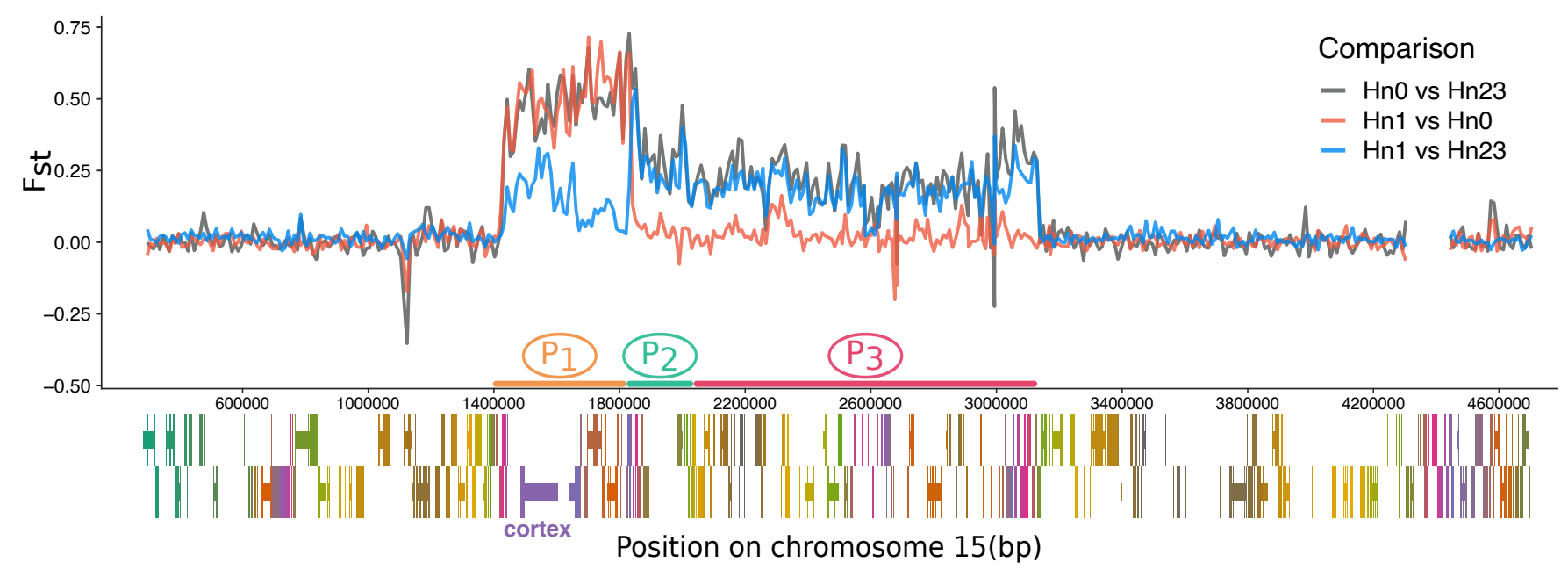

Fig. S8. Fst analysis between the three main supergene alleles : without inversion (Hn0), with $\mathrm{P}_{1}$ inversion (Hn1) and with all three inversion $P_{1}, P 2$ and $P_{3}$ (Hn123)

A "suspension bridge" pattern of differentiation can be observed at $\mathrm{P}_{2}-\mathrm{P} 3$ by comparing $\mathrm{Hn} 123$ to $\mathrm{Hn} 0$ and $\mathrm{Hn} 1$ haplotypes, suggesting the rare occurrence of recombination around the center of the inversion, as predicted by (5). A peak of differentiation can be seen between $\mathrm{Hn} 1$ and $\mathrm{Hn} 123$ around the gene cortex, which controls melanic variations of the wing pattern in Heliconius butterflies (6). This peak was unexpected since these two classes of haplotypes have the same genomic orientation (P1 inversion) in this region. Moreover, this region also show the highest differential gene expression when comparing Hn1 to Hn123 (Sup. Fig. S5). Analyses of assemblies as well as of read coverage (data not shown) do not support the presence of major rearrangements between Hn1 and $\mathrm{Hn} 123$ at this position, suggesting that this peak of differentiation on cortex is caused by selection on wing pattern divergence rather than recombination suppression via structural variation. 


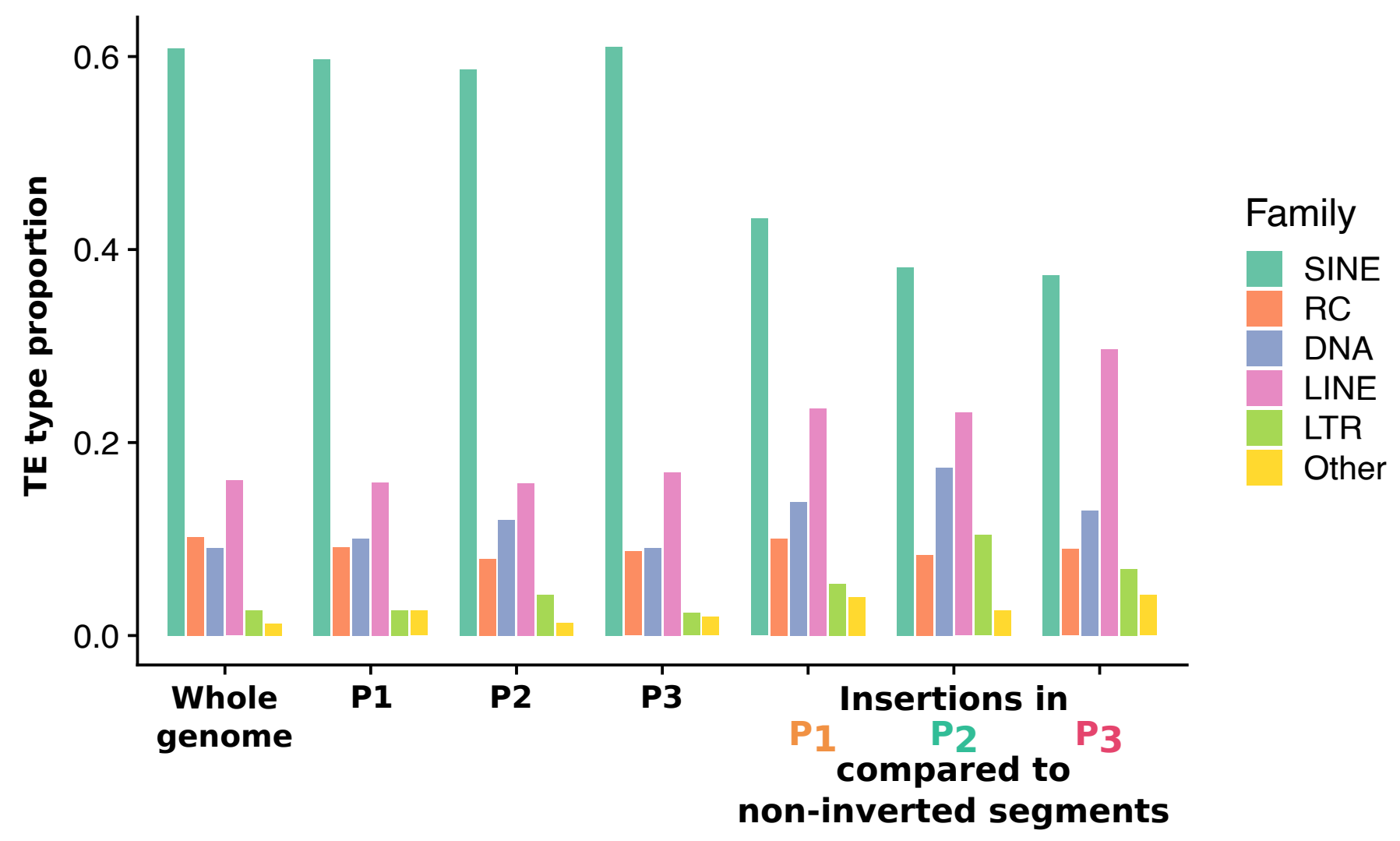

Fig. S9. Proportion of TE classes in whole genome, inversions, and insertions in inversions 
bioRxiv preprint doi: https://doi.org/10.1101/736504; this version posted August 15,2019 . The copyright holder for this preprint (which was not certified by peer review) is the author/funder, who has granted bioRxiv a license to display the preprint in perpetuity. It is made available under aCC-BY-NC-ND 4.0 International license.
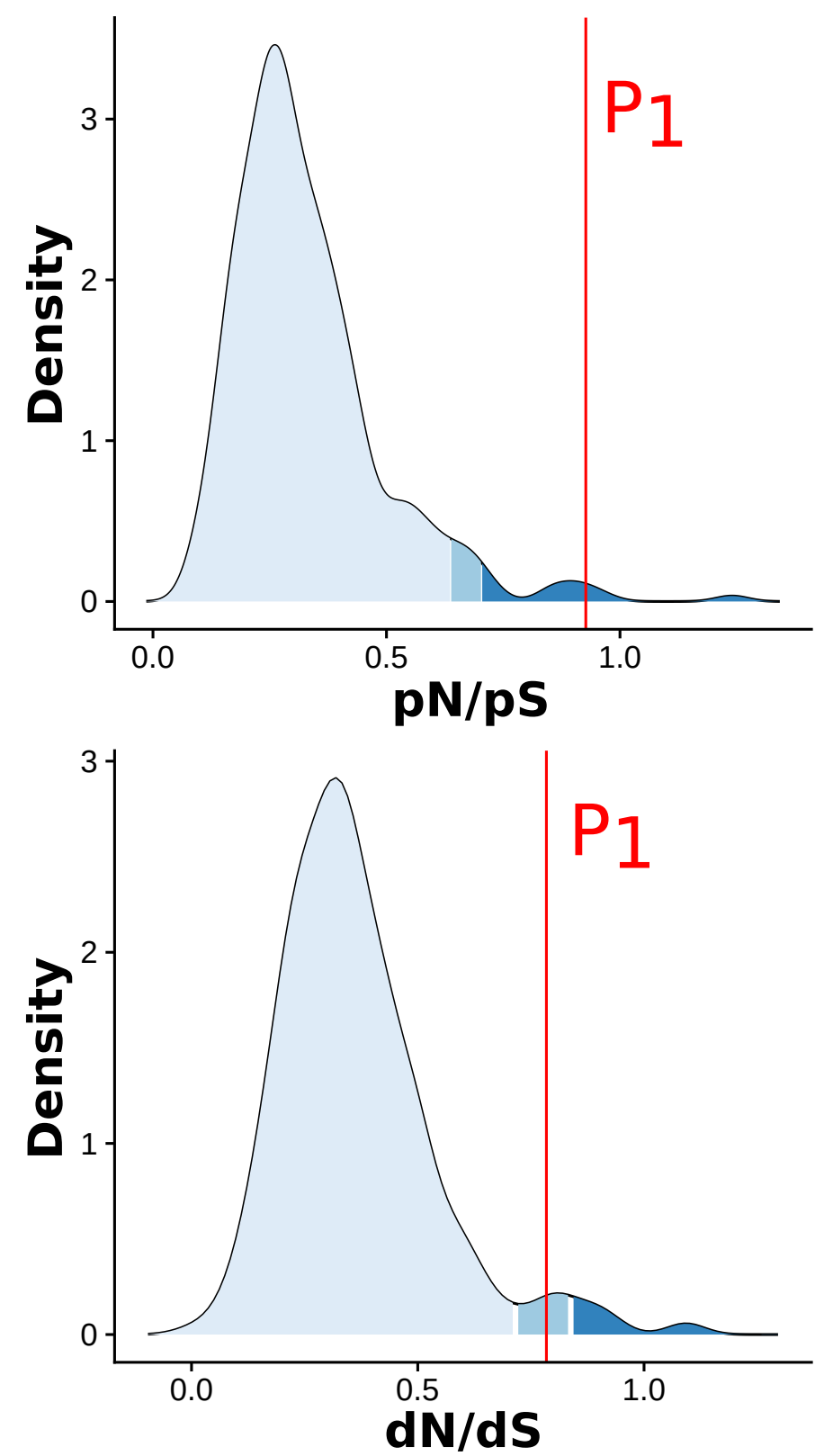

Fig. S10. Mutation accumulation analysis on $\boldsymbol{H}$. pardalinus.

Density curve representing the whole genome distribution computed on 500 kb windows across $12 H$. pardalinus specimens. $\mathrm{P}_{1}$ shows an increase in non-synonymous polymorphisms and substitutions çompared to whole genome. 


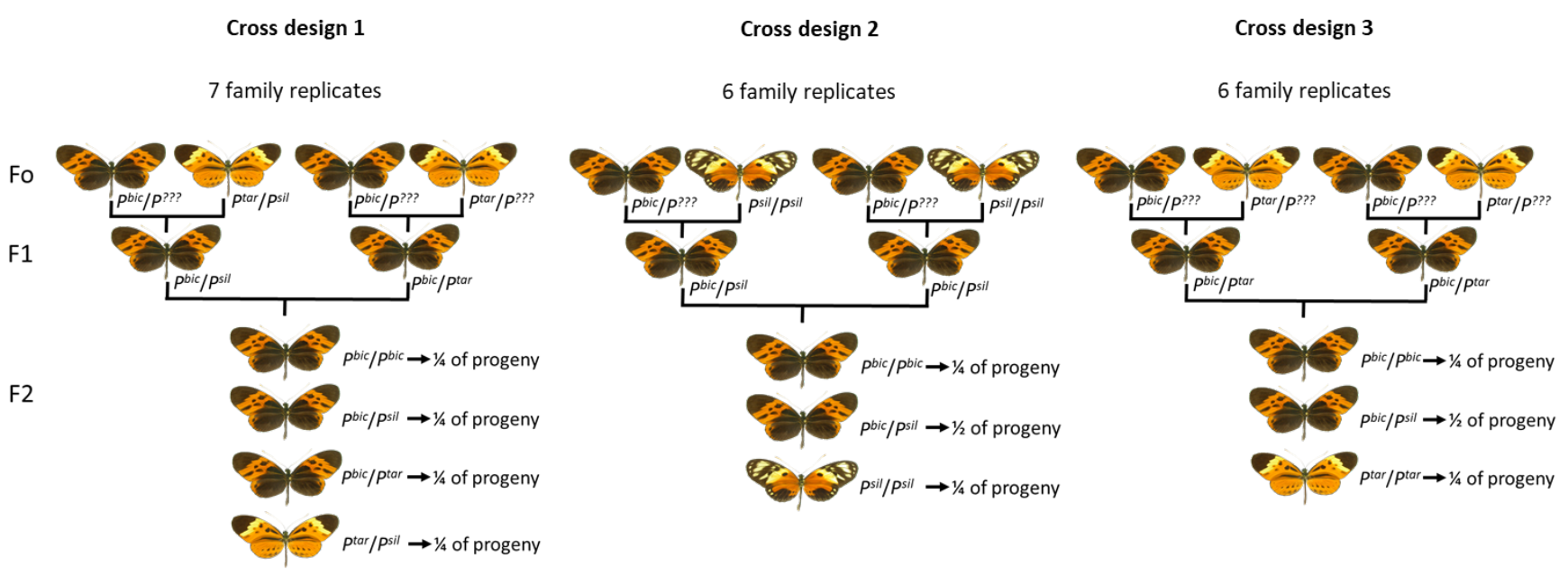

Fig. S11. Experimental crosses designed to assess the survival of the larvae of the distinct genotypes at the supergene $P$.

\section{Supplementary Note 2: Tables}

\begin{tabular}{|l|l|l|l|l|l|l|l|l|l|l|}
\hline Position & Whole genome & \multicolumn{3}{|c|}{ P1 } & \multicolumn{3}{|c|}{ P2 } & \multicolumn{2}{|c|}{ P3 } \\
\hline Samples & H. numata & Hn1-Hn123 & HnO & Hn1-Hn123 common Hpa & unique Hn1/Hn123 & Hpa & Hn123 & Hn0-Hn1 & Hn123 & Hn0-Hn1 \\
\hline pN/pS & 0.36 & 0.84 & 0.61 & 0.629 & 0.97 & 0.92 & 0.55 & 0.31 & 0.49 & 0.33 \\
dN/dS & 0.44 & 0.47 & 0.45 & 1.33 & 0.000 & 0.78 & 0.36 & 0.46 & 0.33 & 0.41 \\
\hline DoS & 0.027 & -0.14 & -0.065 & 0.18 & -0.49 & -0.041 & -0.087 & 0.077 & -0.079 & 0.039 \\
\hline
\end{tabular}

Fig. S12. Accumulation of deleterious variants in inversions.

$\mathrm{dN} / \mathrm{dS}, \mathrm{pN} / \mathrm{pS}$ and Direction of Selection computed on the whole genome or only on segments $\mathrm{P}_{1}, \mathrm{P}_{2}$, or $\mathrm{P}_{3}$. Only samples homozygotes for the ancestral or the inverted gene order are used for the analysis. $\mathrm{HnO}$ display the ancestral gene order at $\mathrm{P}_{1}, \mathrm{P}_{3}$ and $\mathrm{P}_{3}$. $H n 1$ are inverted at $P_{1}$ and non-inverted at $P_{2}$ and $P_{3}$. Hn123 are inverted at $P_{1}, P_{2}$, and $P_{3}$. Because $P_{1}$ was introgressed from $H$. pardalinus ( $\mathrm{Hpa}$ ), we were able estimate parameters on mutations that are unique to $\mathrm{Hn} 1-\mathrm{Hn} 123$, which occurred after the inversion formation, and on mutations that are common to $\mathrm{Hn} 1-\mathrm{Hn} 123$ and $\mathrm{Hpa}$, which occurred before the introgression. Inverted segments consistently show a more negative direction of selection compared to non-inverted segments and a higher $\mathrm{pN} / \mathrm{pS}$ ratio, suggesting a lower efficiency of selection to purge deleterious variants in inversion. Contrarly, $\mathrm{dN} / \mathrm{ds}$ ratio are slightly lower in inverted compared to non-inverted segments. $\mathrm{P}_{1}$ segments help to understand this pattern. Non-synonymous SNPs that occurred in coding region of $P_{1}$ in $\mathrm{Hpa}$ before the introgression ("Hn1-Hn123 common Hpa") underwent a very high rate of fixation in $\mathrm{Hn} 1-\mathrm{Hn} 123$ (dN/dS=1.33), but none of the SNPs that occurred in $\mathrm{Hn} 1-\mathrm{Hn} 123$ after the introgression is fixed ( $\mathrm{dN} / \mathrm{dS}=0,000)$. This suggest that the indermediate $\mathrm{dN} / \mathrm{dS}$ values observed at inversions may result from the balance between the very high rate of fixation during inversions formation (and introgression) and the reduction of fixation rate during their subsequent evolution, likelly because of recombination suppression. 
bioRxiv preprint doi: https://doi.org/10.1101/736504; this version posted August 15,2019 . The copyright holder for this preprint (which was not certified by peer review) is the author/funder, who has granted bioRxiv a license to display the preprint in perpetuity. It is made available under aCC-BY-NC-ND 4.0 International license.

\begin{tabular}{|c|c|c|c|c|c|c|}
\hline Sample & 41(PJ16-53) & 40(PJ16-59) & 38(PJ16-49) & 37(PJ16-45) & 36(PJ16-81) & 35(PJ16-36) \\
\hline Conservation & Snap Frozen & Snap Frozen & Snap Frozen & Snap Frozen & Snap Frozen & Snap Frozen \\
\hline Allele/Morph & Seraphion*Silv & Ele Auto & Silv Auto & Isa Auto & Silv (wild) & Bic (wild) \\
\hline READS (M) & 110.00 & 110.00 & 110.00 & 110.00 & 110.00 & 110.00 \\
\hline MEAN READ LEN (b) & 138.50 & 138.50 & 138.50 & 138.50 & 138.50 & 138.50 \\
\hline RAW COV (x) & 27.31 & 55.59 & 54.27 & 54.61 & 56.67 & 28.01 \\
\hline EFFECTIVE COV (x) & 20.32 & 41.23 & 40.10 & 40.05 & 47.83 & 23.44 \\
\hline READ TWO Q30 (\%) & 86.27 & 86.29 & 85.16 & 85.93 & 90.52 & 90.14 \\
\hline MEDIAN INSERT (b) & 343.00 & 350.00 & 333.00 & 352.00 & 352.00 & 346.00 \\
\hline PROPER PAIRS (\%) & 90.46 & 90.58 & 90.08 & 90.35 & 90.77 & 90.50 \\
\hline BARCODE FRACTION & 1.00 & 1.00 & 1.00 & 1.00 & 1.00 & 1.00 \\
\hline EST GENOME SIZE (Mb) & 604.10 & 296.84 & 304.03 & 302.14 & 291.16 & 589.03 \\
\hline REPETITIVE FRAC (\%) & 16.93 & 5.96 & 6.35 & 6.05 & 5.09 & 17.74 \\
\hline HIGH AT FRACTION (\%) & 0.65 & 0.68 & 0.66 & 0.67 & 0.67 & 0.64 \\
\hline GC CONTENT (\%) & 32.78 & 32.66 & 32.80 & 32.86 & 32.73 & 32.69 \\
\hline DINUCLEOTIDE (\%) & 0.02 & 0.01 & 0.01 & 0.01 & 0.02 & 0.01 \\
\hline MOLECULE LEN (Kb) & 62.55 & 61.32 & 66.40 & 61.32 & 82.65 & 70.48 \\
\hline P10 & 321.15 & 387.62 & 305.06 & 301.82 & 781.47 & 449.21 \\
\hline HETDIST (b) & 44.00 & 64.00 & 56.00 & 66.00 & 102.00 & 60.00 \\
\hline UNBAR (\%) & 8.14 & 8.39 & 8.33 & 8.63 & 5.46 & 5.78 \\
\hline BARCODE N50 & 88.00 & 88.00 & 92.00 & 94.00 & 124.00 & 94.00 \\
\hline DUPS (\%) & 16.54 & 17.50 & 17.37 & 17.94 & 6.68 & 7.21 \\
\hline PHASED (\%) & 61.56 & 64.51 & 64.50 & 64.59 & 75.36 & 67.12 \\
\hline LONG SCAFFOLDS (K) & 4.85 & 3.53 & 3.39 & 3.12 & 3.71 & 5.88 \\
\hline EDGE N50 (Kb) & 20.55 & 25.16 & 24.91 & 25.08 & 24.99 & 20.98 \\
\hline CONTIG N50 (Kb) & 58.53 & 83.73 & 86.61 & 91.67 & 82.93 & 53.21 \\
\hline PHASEBLOCK N50 (Kb) & 1.04 & 997.36 & 967.55 & 1.34 & 1.13 & 887.14 \\
\hline SCAFFOLD N50 (Kb) & 170.96 & 497.61 & 597.63 & 781.88 & 530.17 & 115.52 \\
\hline MISSING 10KB (\%) & 16.49 & 13.66 & 13.60 & 12.97 & 11.68 & 15.39 \\
\hline ASSEMBLY SIZE (Mb) & 280.97 & 280.95 & 287.83 & 285.36 & 297.63 & 302.95 \\
\hline Complete BUSCO (\%) & & 96.2 & & 96.5 & 97.1 & 96.5 \\
\hline Single-copy BUSCO (\%) & & 92.2 & 91.9 & 92.0 & 90.9 & 89.4 \\
\hline Duplicated BUSCOs (\%) & & 4.0 & 5.1 & 4.5 & 6.2 & 7.1 \\
\hline Fragmented BUSCOs (\%) & & 2.1 & 1.7 & 1.9 & 1.7 & 2.0 \\
\hline Fragmented BUSCOs (\%) & & 1.7 & 1.3 & 1.6 & 1.2 & 1.5 \\
\hline
\end{tabular}


bioRxiv preprint doi: https://doi.org/10.1101/736504; this version posted August 15,2019 . The copyright holder for this preprint (which was not certified by peer review) is the author/funder, who has granted bioRxiv a license to display the preprint in perpetuity. It is made available under aCC-BY-NC-ND 4.0 International license.

\begin{tabular}{|c|c|c|c|c|c|c|}
\hline Sample & 30(PJ16-106) & 29(PJ16-52) & 28(VL13-73) & 27(VL13-13) & 26(VL13-114) & 25(VL13-17) \\
\hline Conservation & Snap Frozen & Snap Frozen & DMSO & DMSO & DMSO & DMSO \\
\hline Allele & Tar auto & III Auto & Bic Auto & Arc Auto & Tar Auto & Aur Auto \\
\hline READS (M) & 110.00 & 110.00 & 110.00 & 99.08 & 110.00 & 108.63 \\
\hline MEAN READ LEN (b) & 138.50 & 138.50 & 138.50 & 138.50 & 138.50 & 138.50 \\
\hline RAW COV (x) & 55.78 & 55.66 & 57.05 & 51.41 & 56.48 & 48.83 \\
\hline EFFECTIVE COV $(x)$ & 42.79 & 44.40 & 47.12 & 36.49 & 45.42 & 28.35 \\
\hline READ TWO Q30 (\%) & 88.16 & 89.05 & 90.05 & 85.38 & 89.24 & 79.69 \\
\hline MEDIAN INSERT (b) & 351.00 & 359.00 & 366.00 & 375.00 & 351.00 & 355.00 \\
\hline PROPER PAIRS (\%) & 91.43 & 91.38 & 91.48 & 91.40 & 91.22 & 91.34 \\
\hline BARCODE FRACTION & 1.00 & 1.00 & 1.00 & 1.00 & 1.00 & 1.00 \\
\hline EST GENOME SIZE (Mb) & 295.78 & 296.45 & 289.20 & 289.11 & 292.14 & 333.72 \\
\hline REPETITIVE FRAC (\%) & 7.14 & 6.76 & 4.67 & 6.51 & 5.19 & 9.94 \\
\hline HIGH AT FRACTION (\%) & 0.71 & 0.70 & 0.70 & 0.72 & 0.68 & 0.71 \\
\hline MOLECULE LEN (Kb) & 45.49 & 54.96 & 27.12 & 22.67 & 32.44 & 23.36 \\
\hline P10 & 291.26 & 470.06 & 148.18 & 78.53 & 197.76 & 54.97 \\
\hline HETDIST (b) & 84.00 & 68.00 & 90.00 & 73.00 & 89.00 & 92.00 \\
\hline UNBAR (\%) & 7.53 & 6.68 & 5.92 & 8.86 & 6.57 & 12.81 \\
\hline BARCODE N50 & 76.00 & 76.00 & 78.00 & 68.00 & 86.00 & 74.00 \\
\hline DUPS (\%) & 15.15 & 11.20 & 8.56 & 21.32 & 11.00 & 35.08 \\
\hline PHASED (\%) & 66.59 & 67.85 & 72.86 & 60.00 & 71.15 & 50.08 \\
\hline LONG SCAFFOLDS (K) & 3.90 & 4.58 & 5.90 & 6.00 & 4.86 & 4.34 \\
\hline EDGE N50 (Kb) & 23.67 & 22.54 & 18.95 & 13.95 & 20.38 & 14.47 \\
\hline CONTIG N50 (Kb) & 91.35 & 86.99 & 60.78 & 51.59 & 77.63 & 66.64 \\
\hline PHASEBLOCK N50 (Kb) & 1.14 & 777.63 & 370.01 & 140.68 & 675.16 & 109.61 \\
\hline SCAFFOLD N50 (Kb) & 282.53 & 205.38 & 84.54 & 62.77 & 133.10 & 94.00 \\
\hline MISSING 10KB (\%) & 13.41 & 14.59 & 14.53 & 23.16 & 12.49 & 21.87 \\
\hline ASSEMBLY SIZE (Mb) & 282.34 & 294.09 & 295.26 & 252.58 & 294.98 & 245.39 \\
\hline Complete BUSCO (\%) & 96.7 & 96.2 & 94.9 & 91.7 & 96.3 & 95.0 \\
\hline Single-copy BUSCO (\%) & 91.9 & 90.1 & 86.6 & 87.0 & 90.5 & 91.1 \\
\hline Duplicated BUSCOs (\%) & 4.8 & 6.1 & 8.3 & 4.7 & 5.8 & 3.9 \\
\hline Fragmented BUSCOs (\%) & 1.9 & 2.1 & 3.6 & 5.4 & 2.1 & 2.9 \\
\hline Fragmented BUSCOs (\%) & 1.4 & 1.7 & 1.5 & 2.9 & 1.6 & 2.1 \\
\hline
\end{tabular}

Fig. S13. Summary of genome assemblies quality 
bioRxiv preprint doi: https://doi.org/10.1101/736504; this version posted August 15, 2019. The copyright holder for this preprint (which was not certified by peer review) is the author/funder, who has granted bioRxiv a license to display the preprint in perpetuity. It is made available under aCC-BY-NC-ND 4.0 International license.

\section{Bibliography}

1. Suzanne V Saenko, Mathieu Chouteau, Florence Piron-Prunier, Corinne Blugeon, Mathieu Joron, and Violaine Llaurens. Unravelling the genes forming the wing pattern supergene in the polymorphic butterfly heliconius numata. EvoDevo, 10(1):1-12, 2019.

2. Mark D Robinson, Davis J McCarthy, and Gordon K Smyth. edger: a bioconductor package for differential expression analysis of digital gene expression data. Bioinformatics, 26(1):139-140, 2010.

3. Alexandros Stamatakis. Raxml version 8: a tool for phylogenetic analysis and post-analysis of large phylogenies. Bioinformatics, 30(9):1312-1313, 2014.

4. Paul Jay, Annabel Whibley, Lise Frézal, María Ángeles Rodríguez de Cara, Reuben W. Nowell, James Mallet, Kanchon K. Dasmahapatra, and Mathieu Joron. Supergene Evolution Triggered by the Introgression of a Chromosomal Inversion. Current Biology, 28(11):1839-1845.e3, June 2018. ISSN 0960-9822. doi: 10.1016/j.cub.2018.04.072.

5. Mark Kirkpatrick. The evolution of genome structure by natural and sexual selection. Journal of Heredity, 108(1):3-11, 2016.

6. Nicola J Nadeau, Carolina Pardo-Diaz, Annabel Whibley, Megan A Supple, Suzanne V Saenko, Richard WR Wallbank, Grace C Wu, Luana Maroja, Laura Ferguson, Joseph J Hanly, et al. The gene cortex controls mimicry and crypsis in butterflies and moths. Nature, 534(7605):106, 2016. 